No. 2013-06

\title{
Per-Capita Income as a Determinant of International Trade and Environmental Policies
}

\author{
James R. Markusen \\ University of Colorado, Boulder \\ Hitotsubashi University, Tokyo, Japan
}

\begin{abstract}
International trade policy analysis has tended to focus on the production side of general equilibrium, with policies such as a tariff or carbon tax affecting international and internal income distributions through a Heckscher-Ohlin nexus of factor intensities and factor endowments. Here I move away from this structure to focus on demand, preferences, and endogenous policy in a trade/environment setting by assuming a high income elasticity of demand for environmental quality. I show how both non-cooperative and cooperative abatement policies in a two-country (rich and poor) setting are affected by nonhomotheticity. I examine "issue linking" in international bargaining, in which one country is both large and rich, and hence has both a high tariff and a high abatement effort in a noncooperative equilibrium. Several cooperative bargaining agreements are computed under alternative assumptions about linking or separating trade and environment negotiations. A final exercise considers "policy leakage”, in which one country has an incentive to reduce its optimal abatement effort when the other country increases its effort. The paper will also introduce many readers to a new solver in GAMS for a class of problems referred to as MPECs: mathematical programming with equilibrium constraints. This problem class has wide applications in economics, including solving for multiple optimal tax rates to provide public goods, redistribute income, internalize externalities, exploit monopoly power in trade and so forth, when the underlying general-equilibrium model is a set of constraints on the optimization problem.
\end{abstract}

\section{Draft 0, October 19, 2012}

I have not written a literature review for this draft, and am currently seeking and reading related papers. I am especially interested in finding empirical work that estimates something like an income elasticity of demand for environmental quality. Please send references with attached notes explaining their relevance.

This paper originated following an invitation to present a paper at the conference Environmental Protection and Sustainability Forum, held at the University of Exeter April 13-15, 2011, which reignited a long-dormant interest in trade policy, more specifically trade and the environment. I thank Michael Finus and Christos Kotsogiannis of the University of Exeter for their invitation and their hard work in organizing an excellent conference. The first draft was finally written while a visitor at Hitotsubashi University, and I thank my colleagues there for a delightful and productive three months. 


\section{Introduction}

Much of the literature on trade policy concentrates on the production side of general equilibrium. In the trade/environment literature for example, a typical model might involve the nexus among factor intensities in production, factor endowments of countries, and pollution intensities across goods. A common question might be how changes in trade or environmental policy of one country then change total world pollution and the distribution of pollution emissions across countries (e.g., the carbon leakage and pollution-haven literatures). Considerations of the role and determinants of the demand for environmental quality across countries and hence endogenous policy are less featured, with the exception of a few papers on the environmental Kuznets curve.

This paper develops a model of non-homothetic preferences in which environmental quality has a high income elasticity of demand. At the same time, the usual production side factors just mentioned are neutralized via the use of a novel constant elasticity of substitution transformation function. Global, trans-boundary pollution depends only on both countries' total production and resources withdrawn from production are used in an abatement activity, financed by a non-distortionary tax. Comparative advantage in two consumption goods links the countries through trade, such that more abatement by either country shifts world commodity prices in that country's favor by withdrawing resources from production.

The improved terms of trade partly compensate the environmentally conscious country by shifting part or even half of the burden of abatement in terms of reduced commodity consumption onto the other country. This burden sharing is increasing in a parameter determining the comparative advantage spread between the countries: full specialization in the two goods generates full consumption reduction sharing when only one country increases abatement. No comparative advantage and hence no goods trade means a country with no intervention is a complete free rider on the country increasing abatement.

This production setup allows us to concentrate on the role of per-capita income and differences in per-capita income across countries in determining optimal cooperative and non-cooperative policy outcomes. I develop the basic intuition for later results by showing that the model produces (as intuitively expected) a non-monotonic Kuznets curve: as a country's productivity rises, environmental quality at first deteriorates, then begins to increase as it begins an abatement effort, and eventually passes the quality level originally prevailing when the country was poor.

Next, we examine non-cooperative and cooperative outcomes with respect to abatement efforts by two countries of equal total income. Allowing the per-capita income of the countries to differ holding total income constant (e.g., one country has fewer but more productive households), the Nash non-cooperative policy outcome has a higher abatement effort by the high-income country and a lower effort by the poor country relative to when both countries have identical per-capita incomes. The same is true for a cooperative Nash bargaining outcome using the non-cooperative outcome as the disagreement outcome. This cooperative outcome is contrasted to an outcome that maximizes the product of the two countries utilities and to a Rawlsian outcome which maximizes the minimum of the two countries' utility gains over no intervention by either country. 
Two further experiments are conducted on this question. In the first alternative to the base case, comparative advantage is eliminated so that there is no trade and no effect of one country's abatement on the terms of trade. This reduces the non-cooperative abatement effort of both countries, since a small increase in abatement no longer shifts the terms of trade in that country's favor. The cooperative outcome, on the other hand, is close to that in the comparative-advantage case, since cooperation helps internalize the terms-of-trade externality in the comparative-advantage case. However, I show that it can now be the poor country that gains more at both the cooperative and non-cooperative outcome relative to zero abatement by both countries (it does not have a terms-of-trade loss).

In the second alternative case, the difference in the per-capita income of the two countries is widened considerably (returning to base-case comparative advantage). Obvious results follow about equilibrium cooperative and non-cooperative abatement efforts. But one interesting result is that the poor country may be made worse off by even a modest abatement effort by the rich country, since the term-of-trade deteriorating for the poor country may outweigh the smaller benefits of any spillover improvement to its environment.

Suppose that countries agree on an "equal sharing rule", by which I mean that each country agrees that they will each cut their emissions by the same proportion. Having adopted this rule, they bargain on the level of the proportional cut. I illustrate that the maximum cut that the poor country will agree on (the one that leave it no worse off than no cut at all) falls as its per-capita income falls. At some point, no joint cut can make it better off so that the cut that is adopted is zero.

The paper then turns to "issue linking" in international bargaining. Specifically, there is the standard motive for protection in that an import tariff improves a country's terms of trade. Is there a role for linking together bargaining on abatement efforts with trade liberalization? A clear possibility occurs when the rich country is also large, so that it will have a high tariff in a Nash equilibrium in tariff rates, as well as a high abatement tax. It is possible that the countries can benefit if the large country trades a lower tariff for the poor country increasing its abatement effort.

Using a relatively novel optimization solver in GAMS, I model the generalequilibrium policy problem as an MPEC (mathematical programming with equilibrium constraints). In a non-cooperative outcome, each country chooses a tariff and pollution tax to maximizing its utility given the tariff and tax of the other country, with the two-country general-equilibrium model as a constraint set. In a cooperative outcome, the Nash bargaining function is maximized with respect to the four policy instruments, again with the generalequilibrium model as the constraint set.

The base case has country h having five times both the total income and per-capita income of country s. The non-cooperative Nash equilibrium has a high tax in tariff for n, a low tariff and a zero abatement tax for country s. From this equilibrium, I calculate three two-instrument bargains: (1) an isolated (unlinked) agreement on tariffs, (2) an isolated agreement on abatement taxes, and (3) a bargain in which $n$ lowers its tariff in exchange for a an abatement effort by country s. I then calculate a cooperative outcome in which all four instruments are negotiated together. These two experiments produce outcomes which have quite different values for the four instruments. We will also see that the disagreement 
outcome matters a lot; specifically, whether the Nash equilibrium is the disagreement outcome for bargaining or whether the no-intervention equilibrium is used as the disagreement outcome (country bargaining starting from scratch).

The paper concludes with an example of "policy leakage": the incentive for one country to free ride on the abatement effort of its trading partner. Again formulating the problem as an MPEC, I solve for the level of the poor country's optimal abatement tax for each (exogenous) level of the rich country's tax. Not surprisingly, the former is falling in the latter, and the leakage rate, the shortfall in emissions relative to those that occur holding the poor country's tax constant, is around $50-60 \%$ for the specific parameter values used.

I will not attempt a literature review in this first draft, though I have attached a number of references I have come across to date. Don't get mad, get even: send me references and describe how they fit in. Clearly, Copeland and Taylor's (2004) review article is an important starting point. But very few papers seem to directly ask questions about the income elasticity of demand for environmental quality. Although their focus is different from mine, Broner, Bustos and Carvalho (2012) have shown a relationship between environmental standards and per-capita income (again, not their focus however), using the national standards on the maximum lead content of gasoline (petrol) across countries. I have gone to the source of this data (Lovei 1998) and show it in a plot against per-capita income for the same year as the lead-content data (1996) from World Bank statistics in Plot 1. I am not passing this off as sophisticated econometrics, but the negative relationship (meaning higher standards in rich countries) is economically and statistically strong.

\section{Non-homotheticity and Trade Policy: an Application to Trade and the Environment}

In this section, I consider an international policy question that is of current interest: the relationship between trade policy and international environmental policy with a global pollutant such as $\mathrm{CO}_{2}$. Assume that we have two final consumption goods $\left(X_{1}, X_{2}\right)$, one environmental good $(E)$, and two countries $(n, s)$, where $n$ (north) will be the higher percapita income country.

Final goods are produced by a CET (constant elasticity of transformation) technology, with one input $L$, with $L_{z}$ denoting the total efficiency units of labor allocation to production. Efficiency units are the number of households times productivity per household.

$$
Z=A\left(\sum_{i} a_{i} X_{i}^{\beta}\right)^{\frac{1}{\beta}}=L_{z} \quad \infty \geq \beta \geq 1, \quad \sigma=\frac{1}{\beta-1}
$$

where $\sigma$ is the elasticity of transformation along the production frontier. Z can be thought of as the production equivalent of the "composite commodity" used in the standard DixitStiglitz model of product differentiation. Why this is useful should become clear shortly.

Equation (1) is awkward for calibrating the parameters to specific numerical values, so general-equilibrium modelers generally write this in "calibrated share form", where the 
parameters are all easily derived from observed prices and quantities. Let superscript ' 0 ' denoted observed quantities and prices, and let prices of $Z, X_{1}$, and $X_{2}$ be denoted by $p$ 's.

$$
\frac{Z}{Z^{0}}=\left(\sum_{i} \alpha_{i}\left(\frac{X_{i}}{X_{i}^{0}}\right)^{\beta}\right)^{\frac{1}{\beta}} \quad \alpha_{i}=\frac{p_{i}^{0} X_{i}^{0}}{p_{z}^{0} Z^{0}} \quad \sum_{i} \alpha_{i}=1
$$

Suppose that we observe expenditures on the $X_{i}$ and the total value of output, which will be the expenditure on $Z$. We can choose units so that all prices equal one initially. Second, multiply both sides through by $Z^{0}$, so that (2) can be written as:

$$
Z=\left(\sum_{i} \alpha_{i}\left(\frac{X_{i}}{X_{i}^{0}}\right)^{\beta}\right)^{\frac{1}{\beta}} Z^{0}=\left(\sum_{i} \alpha_{i}\left(\frac{X_{i}}{X_{i}^{0} / Z^{0}}\right)^{\beta}\right)^{\frac{1}{\beta}} \quad \alpha_{i}=\frac{p_{i}^{0} X_{i}^{0}}{p_{z}^{0} Z^{0}}=\frac{X_{i}^{0}}{Z^{0}}
$$

so that the $\alpha_{i}$ 's are the initial observed shares of the $X_{i}$ 's in the value of production. With units chosen such that prices are one initially, this simplifies to

$$
Z=\left(\sum_{i} \alpha_{i}\left(\frac{X_{i}}{\alpha_{i}}\right)^{\beta}\right)^{\frac{1}{\beta}}=\left(\sum_{i} \alpha_{i}\left(\frac{X_{i}}{\alpha_{i}}\right)^{\frac{\sigma+1}{\sigma}}\right)^{\frac{\sigma}{\sigma+1}}=L_{z}
$$

This transformation function is derived in an appendix to the paper, which also shows two further results. First, the unit revenue or national-product function (the production equivalent of the expenditure function) is given by

$$
p_{z}=r(p)=\left(\sum_{i} \alpha_{i} p_{i}^{\sigma+1}\right)^{\frac{1}{\sigma+1}}
$$

Second, the unit supply functions are found by applying Shepard's lemma to (5):

$$
x_{i}=\alpha_{i} p_{i}^{\sigma}\left(\sum_{j} a_{j} p_{j}^{\sigma+1}\right)^{\frac{1}{\sigma+1}-1}=\alpha_{i} p_{i}^{\sigma}\left(\sum_{j} a_{j} p_{j}^{\sigma+1}\right)^{\frac{-\sigma}{\sigma+1}}=\alpha_{i}\left(\frac{p_{i}}{r(p)}\right)^{\sigma}
$$

Relative production of $X_{1}$ and $X_{2}$ then depend on prices and their output levels depend on total labor allocated to produciton.

$$
X_{i}=\quad=\alpha_{i} p_{i}^{\sigma} r(p)^{-\sigma} Z=\alpha_{i}\left(p_{i} / p_{z}\right)^{\sigma} L_{z} \quad \text { since } p_{z}=r(p) \text { in equilibrium }
$$


Let $E^{*}$ be the level or "endowment" of world environmental quality at zero production. Pollution is modeled as a reduction in the endowment of good $E$ and is proportional to the total aggregate output of $Z$ in both countries. Input $L$ can also be used for an abatement activity $A$. Aggregate labor in each country is then divided between production (Z) and abatement $(A): \bar{L}=L_{z}+L_{a}$ where, as before, $\bar{L}$ is effective labor supply.

$$
\begin{aligned}
& \text { Pollution = Reduction in } E \text { endowment }=Z^{n}+Z^{s}=L_{z}^{n}+L_{z}^{s} \\
& \text { Abatement = Addition to the } E \text { endowment }=L_{a}^{n}+L_{a}^{s}
\end{aligned}
$$

For any allocation of labor between production and abatement in the two countries, world environmental quality is then given by:

$$
E=E^{*}-\left(L_{z}^{n}+L_{z}^{s}\right)+\left(L_{a}^{n}+L_{a}^{s}\right)
$$

Abatement is financed by a consumption taxes in $\mathrm{n}$ and $\mathrm{s}: t^{n}, t^{s}$. Thus public policy, via the consumption tax, can determine that allocation of the composite input $L$ between production and abatement. Specifically, the equal taxes on both goods is equivalent to a tax $t$ on the labor input to production. Budget balance then requires tax revenues $t w L_{z}$ to equal abatement expenditures $w L_{a}$ where $w$ is the wage rate. Thus the tax rate (in either country) will equal the ratio of labor in abatement to labor in production.

$$
t=\frac{L_{a}}{L_{z}} \quad \text { or } \quad \frac{t}{1+t}=\frac{L_{a}}{\bar{L}}=\text { share of labor in abatement }\left(L_{z}=\bar{L}-L_{a}\right)
$$

The advantage of this simple model is that it implies "neutrality" in several senses. By neutrality I mean:
$=>\quad$ no pollution-intensive sector
$=>\quad$ no comparative advantage in polluting sector
$=>\quad$ no factor-intensity, factor-endowment issues
$=>\quad$ no pollution-from-consumption-versus-production issue

The dominant model in the trade-and-environment literature has only one sector that pollutes, This leads to policy results that are very sensitive to:
$=>\quad$ which factor is intensive in which good
$=>\quad$ which good is the country's comparative advantage good
$=>\quad$ whether pollution is from consumption or production

Here we avoid these issues. However, at the same time, allowing the $\alpha_{i}$ 's to differ across countries generates a comparative advantage motive for trade and gains from trade in the $X$ 's. This will be important since world prices will change as one country withdraws labor from production in order to increase abatement. This terms-of-trade change in the relative prices of the two $X$ goods will always favor the environmentally conscious country, a 
point I will return to shortly.

Preferences are Stone-Geary, lower case letters for per-capita quantities

$$
u=x_{1}^{\epsilon} x_{2}^{\epsilon}\left(E+e_{0}\right)^{\gamma} \quad 2 \epsilon+\gamma=1
$$

where $e_{0}$ is a positive parameter for each household in each country which creates the nonhomotheticity: up to a critical level of income, there will be no demand for environmental quality. It can be useful to think of $e_{0}$ as an endowment good given to each household which cannot be traded: every household can watch the sunset and that is a perfect substitute for a cleaner environment. $E$ is the (world) environmental good supply and is a pure (non-rivaled and non-excludable) public good. So each consumer in each country gets to consume the entire world supply.

Let $\quad E^{i}$ denotes the demand for environment in country i,

$m^{i}$ is country i's per-capita income

$p_{e}^{i}$ is the price (willingness to pay) by a single household for environment in i.

Consumer optimization yields:

$$
\begin{aligned}
& E^{i}= \max \left[0,(\gamma-1) e_{0}^{i}+\frac{\gamma m^{i}}{p_{e}}\right] \\
& E^{i}>0 \text { iff } m^{i}>\frac{(1-\gamma)}{\gamma} p_{e} e_{0} \equiv m^{0}
\end{aligned}
$$

The result is the one just noted: up to the threshold per-capita income given in (13), there is no demand for environmental quality. Once the threshold income is reached,

$$
E^{i}=(\gamma-1) e_{0}+\gamma \frac{m^{i}}{p_{e}^{i}}
$$

At a constant price, the income elasticity of demand for $E$ is greater than one once the threshold is reached. In equilibrium, $E$ must be the same for all consumers in all countries (perfect global public good). So for (14) to hold, it must be that the willingness to pay $p_{e}$ differs across countries. This (private) willingness to pay can be found by inverting (14).

$$
p_{e}^{i}=\frac{\gamma m^{i}}{E+(1-\gamma) e_{0}}
$$

Since the environment is a public good (non-rivaled and non-excludable), optimal policy depends on the sum of the individual benefits of the good. We can work with either (14) or (15). The right-hand side of (14) can be multiplied by $h^{i}$, the number of household in country i (the aggregate supply of the alternative "sunset" good is proportional to the number 
of households). When this is set equal to the (exogenous) quantity of $E$, the price that produces equality is interpreted as the social willingness to pay, $q_{e}^{i}$.

$$
E^{i}=(\gamma-1) e_{0} h^{i}+\gamma \frac{m^{i}}{q_{e}^{i}} h^{i}
$$

Alternatively, the social value of $E$ is given by multiplying the right-hand side of (15) by $h^{i}$ and the supply of the alternative endowment good (sunsets) is also multiplied by $h^{i}$.

Denoting total income as $M^{i}=m^{i} h^{i}$, gives the same equation as found by inverting (16).

$$
q_{e}^{i}=\frac{\gamma m^{i} h^{i}}{E+(1-\gamma) e_{0} h^{i}}=\frac{\gamma M^{i}}{E+(1-\gamma) e_{0} h^{i}} \quad \text { where } M^{i} \text { is total income of i }
$$

Holding total income constant, an increase in per-capita income is a reduction in the number of households $h^{i}$, and so the social willingness to pay rises. Note that this passes one simple check: if preferences are homothetic such that $e_{0}=0$, then the social willingness to pay depends only on total income and not per-capita income and the value of demand is a constant share of total income: $q_{e}^{i} E=\gamma M^{i}$. Note also that with or without homotheticity, the social price in (17) is greater than the private willingness to pay in (15) for $h>1$.

Assume that there is no pattern of comparative advantage: $\alpha_{j}^{i}=\alpha=0.5$ for all $\mathrm{i}=\mathrm{n}, \mathrm{s}$, $\mathrm{j}=1$, 2. This assumption combined with the equal-shares on $X_{1}$ and $X_{2}$ in the utility function implies that the world prices of $X_{1}$ and $X_{2}$ are equal, so the price of $Z$ is also equalized across countries. There is no motive to trade goods. Let $Z$ be numeraire: its price equals one in both countries as do the prices of $X_{1}$ and $X_{2}$.

Using a consumption tax on $Z$, the efficiency condition for each country individually is that the (social) marginal rate of substitution between $Z$ and $E$ should equal the ratio of marginal costs. Equations (8) above imply that the ratio of marginal costs of an added unit of environment $E$ to the marginal cost of an extra unit of $Z$ equals one. Let $p_{z}{ }^{i}=m c_{z}{ }^{i}$ be the producer price of $Z$ in country $i$. With the consumer price of $Z$ (and of $X$ and $Y$ individually) given by $p_{z}{ }^{n}\left(1+t^{n}\right)$, the environmental distortion from country n's and s's points of view is internalized with a tax such that:

$$
\frac{q_{e}^{n}}{p_{z}^{n}\left(1+t^{n}\right)}=\frac{q_{e}^{s}}{p_{z}^{s}\left(1+t^{s}\right)}=\frac{m c_{e}^{i}}{m c_{z}^{i}}=1 \quad p_{z}^{i}=m c_{z}^{i} \quad i=n, s
$$

A country will wish to have a positive tax if $q_{e}^{i}$ exceeds one at the zero-tax level of $E$.

Assume that both countries have positive taxes. From (16) and (17), the ratio of the tax rates is given by 


$$
\frac{1+t^{n}}{1+t^{s}}=\frac{q_{e}^{n}}{q_{e}^{s}}=\left[\frac{E+(1-\gamma) e_{0} h^{s}}{E+(1-\gamma) e_{0} h^{n}}\right] \frac{M^{n}}{M^{s}}
$$

from which we get the following results:

Result: holding E constant, country n will have the higher tax rate if:

(a) both countries have the same total income but country $n$ has a higher percapita income $\left(M^{n}=M^{s}, h^{n}<h^{s}\right)$.

(b) both countries have the same number of households, but $\mathrm{n}$ has a higher percapita income and therefore higher total income $\left(M^{n}>M^{s}, h^{n}=h^{s}\right)$.

(c) both countries have the same per-capita income, but country n has a higher total income $\left(h^{n}=\rho h^{s}, M^{n}=\rho M^{s}, \rho>1\right)$.

The fact that the relative tax rates depend on country size is due to the pure international public-good nature of the environment. Each country gets the same $E$, so willingness to pay for the fixed quantity is higher in the large country even if per-capita incomes are the same.

Of course, the introduction of this tax will lead to an increase in $E$ for both countries, lowering the willingness to pay for environment: the q's are endogenous to the tax. (18) is just a formula in which the q's depend on the taxes, so we have no idea what the value of the taxes might be. Secondly, (18) does not take into account the effect of withdrawing resources from production to use in abatement on the terms of trade in goods, an effect "neutralized" in our special case. This terms-of-trade effect can partially compensate country $\mathrm{n}$ for the lower production of goods when it uses resources for abatement. Finally, the tax in (18) is not jointly optimal of course, because it does not take into consideration the benefits to country $\mathrm{i}$ from the improved environmental quality by country $\mathrm{j}$, a point I return to later.

In order to understand the terms-of-trade effect, I make some very special assumptions in order to derive a clear expression for the effect of abatement by one country on the terms of trade. First, assume that the elasticity on transformation is zero, so that goods are produced in fixed proportions in each country, with that proportion depending on the country's alpha parameters. Assume that there is free trade in goods, so that the world production ratio equals the (inverse) consumer price ratio in equilibrium (since the goods are Cobb-Douglas symmetric substitutes in consumption). We then have:

$$
\frac{X_{1}^{n}+X_{1}^{s}}{X_{2}^{n}+X_{2}^{s}}=\frac{\alpha_{1}^{n} L_{z}^{n}+\alpha_{1}^{s} L_{z}^{s}}{\alpha_{2}^{n} L_{z}^{n}+\alpha_{2}^{s} L_{z}^{s}}=\frac{p_{2}}{p_{1}}
$$

Let country n withdraw a unit of labor from production. Differentiating (20), we have: 


$$
\frac{\left(\alpha_{2}^{n} L_{z}^{n}+\alpha_{2}^{s} L_{z}^{s}\right) \alpha_{1}^{n}-\left(\alpha_{1}^{n} L_{z}^{n}+\alpha_{1}^{s} L_{z}^{s}\right) \alpha_{2}^{n}}{\left(\alpha_{2}^{n} L_{z}^{n}+\alpha_{2}^{s} L_{z}^{s}\right)^{2}} d L_{z}^{n}=d\left(p_{2} / p_{1}\right)
$$

where we will assume that country $n$ has the comparative advantage in good 1 : $\alpha_{1}^{n}>\alpha_{2}^{n}=\left(1-\alpha_{1}^{n}\right)$ and $\alpha_{2}^{s}>\alpha_{1}^{s}=\left(1-\alpha_{2}^{s}\right)$.

Now make some addition restrictive assumptions. Assume that the countries are identical initially and that there are no initial abatement taxes, so that $L_{z}{ }^{n}=L_{z}{ }^{s}=L_{z}$ where $L_{z}$ is the total endowment of each country. Second, assume symmetry in the comparative advantage parameters such that $\alpha_{1}^{n}=\alpha_{2}^{s}=\left(1-\alpha_{2}^{n}\right)=\left(1-\alpha_{1}^{s}\right)$. Because $\alpha_{1}^{n}+\alpha_{2}^{n}=1$ and $p_{1} / p_{2}=1$ initially, (21) simplifies to (shown in the appendix)

$$
\begin{aligned}
& \left(\alpha_{1}^{n}-\alpha_{2}^{n}\right) \frac{d L_{z}^{n}}{L_{z}^{n}}=\frac{d\left(p_{2} / p_{1}\right)}{\left(p_{2} / p_{1}\right)} \text { or } \\
& -\frac{d\left(p_{1} / p_{2}\right)}{\left(p / p_{2}\right)}=\frac{d\left(p_{2} / p_{1}\right)}{\left(p_{2} / p_{1}\right)}=\left(\alpha_{1}^{n}-\alpha_{2}^{n}\right) \frac{d L_{z}^{n}}{L_{z}^{n}}
\end{aligned}
$$

The effect of country n withdrawing a unit of labor from production $\left(d L_{z}^{n}<0\right)$ is to reduce the relative price of country s's export good $X_{2}$ (country s has a deterioration in its terms of trade) with the size of this effect being proportional to the size of comparative advantage spread.

Two extreme cases are instructive:

$\left(\alpha_{1}^{n}-\alpha_{2}^{n}\right)=0$ : no comparative advantage and hence no trade in goods. Country s has no adverse terms-of-trade effect and benefits from the reduction in admissions from country n.

This is shown in Figure 1a, where the (right angle) production frontiers are initially the same and country n's frontier moves in with labor transferred to abatement. All the reduction in commodity consumption is borne by country $n$ while both countries benefit from an increase in $E$.

$\left(\alpha_{1}^{n}-\alpha_{2}^{n}\right)=1$, that is, $\alpha_{2}^{n}=\alpha_{1}^{s}=0$ : each country is fully specialized. Country s has the maximum possible adverse terms-of-trade effect but does benefit from the reduction in emissions from country $n$.

This is shown in Figure 1b: because of Cobb-Douglas preferences between $\mathrm{X}_{1}$ and $X_{2}$, the world price ratio changes so that both countries share the same reduction in commodity consumption. Fully half the burden of withdrawing resources from production by country $n$ 
is shifted to country s. With Cobb-Douglas demand, each country will have the same income M:

$$
M^{n}=p_{1} X_{1}^{n}=p_{1} L_{z}^{n}=M^{s}=p_{2} X_{2}^{s}=p_{2} L_{z}^{s} \text { since } \frac{X_{1}^{n}}{X_{2}^{s}}=\frac{p_{2}}{p_{1}}
$$

which follows from (10), and the symmetry of the alphas $\left(\alpha_{1}^{n}=\alpha_{2}^{s}=1\right)$.

With identical Cobb-Douglas sub-utility functions over $X_{1}$ and $X_{2}$, the countries will have identical $\left(X_{1}, X_{2}\right)$ consumption bundles regardless of the level of country n's abatement effort. In other words, the change in the terms-of-trade change fully compensates country $n$ (relative to country s) for its unilateral abatement effort. Both countries have an identical consumption loss and the same aggregate improvement in the environment.

If country n has a higher per-capita income ( $L^{n}$ of effect labor is composed fewer but more productive households than country s) then country $n$ gets a bigger boost in welfare than does country s. In fact, if country s is sufficiently poor such that it places only a very small added value to the environmental good, then country s is likely worse off from n's abatement.

\section{The general-equilibrium simulation model}

The model developed above seems simple, but there is a lot of simultaneity. Optimal policy depends on income, for example, and income depends on the policy chosen, both by determining the domestic resources available for production of goods and through the international general-equilibrium terms-of-trade effect. Note, for example, that the simple result in (22) requires severe assumptions and even then it is only locally valid in the neighborhood of zero abatement. Similarly, the simple tax formula in (18) is not very informative in general-equilibrium. (18) is just a formula, it is not a value. So let's turn to a numerical general-equilibrium model to see how per-capita income matters for cooperative and non-cooperative outcomes.

The model belongs to a class of problems loosely known as MPEC: mathematical programming with equilibrium constraints. In our case here, the set of equilibrium constraints is the two-country general-equilibrium model. The latter, in turn, is known as an MCP: mixed complementarity problem. This is a set of weak inequalities with associated non-negative variables such as quantities and prices. When a weak inequality holds as an equality, the complementary variable is positive, zero if the inequality is strict in equilibrium.

The MPEC consists of maximizing some function such as a Nash bargaining function (cooperative) with respect to tax rates (pollution taxes and/or tariffs) subject to the economic equilibrium constraint set. A non-cooperative Nash equilibrium is found by iteration: maximize the welfare of i holding j's taxes constant, then hold i's taxes constant at the solution values and maximize j's welfare, repeat. This converges to a best-response, noncooperative outcome in about eight iterations. Here is a description of the model. 
(A) Alternative objective functions

welfare of country $n$

welfare of country s

joint welfare (or Nash bargaining function)

(B) The mxm economic equilibrium problem (constraint set): 28 inequalities and unknowns

Inequalities

Complementary Variables Number

marginal cost $\geq$ price

production of $Z$ by n, $s$

trade in $X_{1}, X_{2}$ by n,s

welfare in $\mathrm{n}$ and $\mathrm{s}$

abatement activities in $\mathrm{n}$ and $\mathrm{s}$

quantities

quantities of $Z$

2

quantities traded 4

welfare in $\mathrm{n}$ and $\mathrm{s} \quad 2$

quantity of abatement 2

market clearing: supply $\geq$ demand

supply / demand for $Z^{n}, Z^{s}$

supply / demand for $X_{i}$ in n, s

supply / demand for $L$ in $\mathrm{n}$ and $\mathrm{s}$

supply / demand for welfare

supply / demand for abatement in n, s

prices

prices of $Z$ in n, s 2

prices of $X_{i}$ in n, s 4

prices of $L$ in $\mathrm{n}, \mathrm{s} \quad 2$

price index in $n, s \quad 2$

supply / demand for environment good

price of abatement in $\mathrm{n}, \mathrm{s} \quad 2$

willingness to pay in $\mathrm{n}, \mathrm{s} \quad 2$

income balance: income $\geq$ expenditure

income balance for n,s

income in $\mathrm{n}, \mathrm{s}$

auxiliary equations

pollution reduction $=$ abatement

pollution abatement

pollution

pollution $=$ emissions

(C) Additional unmatched variables chosen to optimize welfare:

pollution abatement effort (abatement tax) in countries n, s 2

tariffs imposed by countries $\mathrm{n}, \mathrm{s}$

(D) The MPEC (mathamtical programming with equilibrium constraints)

Maximize objective function, subject to:

pollution abatement taxes and tariffs in $n, s$

mxm economic equilibrium problem constraint set

A sample program, written and solved in GAMS, is provided in appendix two to the paper. 


\section{Policy experiments}

The first policy experiment is shown in Figure 2. This considers environmental quality as a function of per-capita income, where I make the countries identical (in total and in per-capita incomes) for simplicity. Productivity or "effective" labor units per household are increased holding the number of households constant. The MPEC solves for the optimal taxes or abatement effort at each level of income (productivity).

This produces a non-monotonic Kuznets curve in Figure 2 as we expect. At very low levels of per-capita income, there is no demand for abatement or additional environmental quality and the latter falls with increases in productivity. At a critical level around 0.9 in this experiment, there is a positive demand for additional environmental quality and the tax kicks in. The tax rate rises steadily thereafter due to the non-homotheticity, and is equal to 0.25 on the right-hand boundary where environmental quality is now higher than in the very poor county.

What is perhaps not so obvious is that there is still some non-monotonicity in the Kuznets curve with homothetic demand. This is due to the fact that the initial fixed endowment of $E=E^{*}$ is to high or rather the demand price too low to justify abatement at low income levels. Intuitively, a really poor country would want to sell off some of the environmental good if it could under either homothetic or non-homothetic demand. Adding the non-homotheticity assumption shifts the minimum point to the right in Figure 2 (not shown). If there was no initial endowment of $E, E^{*}=0$, then the homothetic case would produce a constant tax rate at all levels of income such that environmental quality is a linear function of income passing through the origin, while the non-homothetic case continues to look like Figure 2 (from (2), $E$ can go negative provided that $-E<e_{0}$ ). This possibly expected result occurs only when $E^{*}=0$.

The next exercise is to examine how cooperative and non-cooperative policy outcomes depend on per-capita income. Some result are shown in Figure 3. In all cases, the total incomes of the countries are equal. There is a strong pattern of comparative advantage in the case considered, $\alpha_{1}^{n}=\alpha_{2}^{s}=0.9$, and $\sigma=1$. Thus when per-capita incomes and taxes are unequal, there will be a fairly strong terms-of-trade effect that favors country n.

The solid boxes in Figure 3 show an outcome when the two countries have equal percapita incomes (or same number of equally productive households). Each country's (unilateral) optimal tax is shown when the other country's tax is zero as are the noncooperative Nash equilibrium rates. There is no difference in the values of the taxes across countries in this latter equilibrium as we expect to be the case. The (equal) cooperative tax rates are Nash bargaining outcomes where the disagreement outcome is the non-cooperative Nash equilibrium. The cooperative rates are considerably higher than the non-cooperative ones as shown in Figure 3. The terms-of-trade in both outcomes is one and there is no trade in goods.

The second set of outcomes, shown with a slash through the boxes in Figure 3, assumes that country $\mathrm{n}$ has a per-capita income 1.5 times that of country s. Total incomes are the same as in the first case (solid boxes), so country n now has fewer, more productive 
households while s has more, less productive households. Figure 3 shows that the noncooperative equilibrium shifts to a higher tax for country $\mathrm{n}$ and to a lower tax for country $\mathrm{s}$ (as we would expect). The cooperative Nash bargaining outcome using the non-cooperative outcomes as the disagreement point shifts from the equal-per-capita-income scenario in about the same way.

As suggested earlier, country n will be partially, perhaps significantly, compensated for its higher abatement effort by an improvement in its terms of trade. Specifically, the relative price of good $X_{1}$, country n's export good, is 1.12 at the non-cooperative Nash outcome and 1.14 at the cooperative outcome.

Table 1 presents numerical values for these results and compares them to several alternative scenarios. The first three columns of number are the case where country n's percapita income is 1.5 times that of country s as in Figure 3. The first row gives the welfare values when there is no intervention by either country, where these welfare values are normalized at one. The second and third row of Table 1 give the welfare values for the noncooperative and cooperative outcomes, and the lower panel the corresponding tax rates (PTAXN, PTAXS), which are those in Figure 3. Note that the non-cooperative outcome results in a substantial welfare gain over non-intervention: unlike a non-cooperative tariff "war" for example, here the non-cooperation is a failure to internalize a positive rather than a negative externality.

The tax rates that maximize the Cobb-Douglas world welfare function and a Rawlsian welfare function are also shown (world welfare is the minimum of the two countries' welfare levels.). The former is equivalent to a Nash bargaining outcome when the disagreement outcome for both countries is zero. Curiously, the Rawlsian outcome is not very different from the cooperative Nash outcome, but does require a higher tax for country n and a slightly lower one for country s relative to the cooperative outcome. I do not have any intuition to tell me if this is just a "coincidence" or if there is some deeper truth here. Also curious, the tax rates that maximize the Cobb-Douglas index of world welfare are equal (0.35). Here I do think there is a deeper truth. World production efficiency requires equal tax rates, but it is unclear to me why this should be a characteristic of maximizing the Cobb-Douglas index.

An interesting feature of these results is that country $n$ is actually the relative gainer over the no-intervention outcomes (except the Rawlsian one). How much of this is simply due to the fact that country n places a much higher value on the environment at the nointervention point, and how much might be due to the this terms-of-trade effect? In order to examine this question, I compute an scenario in which there is no comparative advantage: $\alpha_{1}^{n}=\alpha_{2}^{s}=0.5$.

Results are shown in columns 4 and 5 of Table 1 . Here we see some significant differences. First, the relative gainer is reversed in the cooperative and non-cooperative Nash outcomes. Now country s is the relative gainer. This verifies the conjecture that the termsof-trade effect that favors the higher-tax country $n$ in columns 1 and 2 is indeed important in determining the relatively larger gains for country $n$ in those columns. Second, note in the lower part of the Table that the non-cooperative rates for both countries are lower when there is no comparative advantage. This is clearly due to the fact that raising your tax rate has no compensating beneficial effect on the terms of trade with no comparative advantage. Third, 
the cooperative Nash is almost unchanged from the comparative-advantage case, presumably because this case internalizes the terms-of-trade externality. The CD maximum rates are also unchanged, because there is no terms-of-trade effect when the countries have the same rates. Fourth, the Rawlsian maximum rate is now lower for country $\mathrm{n}$ and higher for country s. I think that the intuition here is that, starting from the Rawlsian taxes with comparative advantage, removing comparative advantage reduces the welfare of high-tax country $n$ and raises it for country s. The Rawlsian outcome then adjusts n's tax down and s's tax up.

A second alternative case is presented in columns six and seven of Table 1.

Comparative advantage is reinstated, but country n now has nine times the per-capita income of country s. Results are now that country s has a zero tax rate at both the cooperative and non-cooperative Nash outcomes. The non-cooperative outcome is in fact a Pareto optimum: there are no gains from cooperative. Second, note that country s is almost indifferent between the no-intervention outcome and the cooperative or non-cooperative equilibrium. If I push the size difference a little higher, then country s is actually worse off than with no intervention. Country s places little value on improved environmental quality and suffers a negative terms-of-trade effect when country $\mathrm{n}$ imposes its abatement tax. The relative price of country n's export good is 1.22 at the cooperative and non-cooperative tax rate of 0.41 .

Third, there is now a large difference between CD world welfare maximum tax rates and the Rawlsian rates. The CD rates are again equal to one another, while country $\mathrm{n}$ bears all the abatement effort in the Rawlsian equilibrium. As in alternative case 1, the welfare levels of the two countries are not equal in the Rawlsian equilibrium in alternative 2; in fact, they are quite different (there is some rounding error that make the Rawlsian outcome look Pareto inferior to the cooperative one - it isn't). At the Rawlsian equilibrium, any increase in either country's tax makes country s worse off.

The model is then used to consider an experiment in which countries can agreed to bargain over a common level of abatement taxes or, given (10) above, a common share of resources devoted to abatement. The countries are initially identical in total and per-capita incomes, and then the per-capita income of country s is reduced holding its total income constant (more but less productive households). Results are shown in Figure 4, where the common tax rate is on the horizontal axis. Both countries' welfare levels are shown by the curve "country n's welfare" when they have the same per-capita income. Now lower country s's per-capita income to one-fifth and then one-tenth of country n's per-capita income. The curve for country n does not change, while that for country s is flatter and has its maximum at a lower level of per-capita income. When the difference between the countries' per-capita incomes is a factor of ten, country s cannot gain at any common tax rate. Thus having agreed on an "equal sharing rule" and then bargaining on the rate, the outcome is a zero rate when the per-capita-income difference is large. This has some clear applications to situations such as the Kyoto protocol, where there was considerable controversy over whether or not the poor and rich countries should suffer the same proportional cuts in carbon emissions.

Now I turn to issue linking and introduce two additional policy instruments: import tariffs for countries $\mathrm{n}$ and $\mathrm{s}$. We will assume that country $\mathrm{n}$ has five times both the total income and the per-capita income of country s. Comparative advantage is the same as we used earlier: $\alpha_{1}^{n}=\alpha_{2}^{s}=0.9$ and $\sigma=1$. Some results are shown in Figure 5 and more complete results in Table 2. A shorted version of the GAMS program (it doesn't solve for all 
scenarios) is attached at the end of the paper. The no-intervention case shown in the first row of Table 2 fixes the four policy instruments at zero. The joint-welfare function is then essentially a "dummy": the solution to the model is equivalent to simply solving the twocountry general-equilibrium model at zero taxes and tariffs (PTAX denotes pollution (abatement) taxes and TAR denotes tariffs of $n$ and $s$ ). The welfare numbers are normalized at 1.0 in the non-cooperative outcome, but I should note that the difference in the welfare levels is nowhere near a factor of five: n's welfare is about twice that of country s. This is due to a large relative price advantage for country s: the relative price ratio is 0.472 or inverting, the relative price of country s's export good $X_{2}$ is 2.121 .

Tables 2 and Figure 5 then give the non-cooperative Nash equilibrium, where each country jointly chooses its abatement tax and tariff for fixed values of the other country's instruments. This is solved as an iterative MPEC. Country n's welfare is maximized with respect to PTAXN and TARN holding PTAXS and TARS constant. Then the solution values of PATXN and TARN are held constant and the welfare of country s is maximized with respect to PTAXS and TARS. The iteration converges to the non-cooperative Nash equilibrium in about six to eight iterations.

Table 2 and Figure 2 show that, not surprisingly, country n has a high abatement tax and tariff. Country s has a small tariff and a zero abatement tax. Table 2 notes a substantial welfare improvement over no intervention for both countries. However, I imagine a case can easily be produced in which country $s$ is worse off than in the no-intervention equilibrium following the logic of Table 1.

Four cooperative bargaining outcomes are then computed using the Nash equilibrium as a disagreement point in Table 2. The first computes an isolated environmental tax bargain. The second computes an isolated tariff bargain. In each of these two cases, the instruments not under negotiation are held at their non-cooperative Nash levels. One interesting result here is that there are no gains to an isolated environment negotiation. No Pareto improving changes in taxes can help and nothing will come of such a negotiation (sound familiar?). The isolated tariff negotiation does produce a positive result, as country n lowers its tariff significantly in exchange for country s eliminating its tariff.

In the third case using the non-cooperative outcome as a disagreement point (row 5 of Table 2), country n offers a lower tariff in exchange for a positive abatement effort by country s. In my view, this is what some writers and politicians in high-income countries want to do: offer trade liberalization in exchange for environmental and labor standards to poor countries. The joint welfare function WELG (global) is maximized holding PTAXN and TARS at their non-cooperative levels. Results are shown in Table 2 and in Figure 5.

In order to get a feel for the "global" properties of the linking payoff, I also computed this by a brute-force grid search, which is the surface shown in Figure 5 (using only two instruments allows for a nice graphical representation). The non-cooperative equilibrium is on "Country n's tariff” axis with "Country s's ptax" equal to zero. The vertical axis gives the value of the Nash bargaining function, equation WELFAREG in the GAMS program at the end of the paper. Only points that are Pareto improving have positive values for this function and the maximum point of the surface in Figure 5 is of course the payoffs in the Nash bargaining equilibrium. As noted in Table 2 and Figure 5, country n gives up a substantial reduction in its tariff in exchange for an increase in country s's pollution tax from 0.0 to 0.15 . 
Note that country s would rather have an isolated negotiation about trade only, the thing it really cares about, than negotiate over PTAXS for a lower TARN.

Row 6 of Table 2 takes the non-cooperative Nash outcome as a disagreement outcome and computes a cooperative bargaining solution treating all four instruments as endogenous variables. Here the outcome is a zero abatement tax and a zero tariff for country s. Country $\mathrm{n}$ bears the burden of abatement and, in exchange, retain a high tariff but substantially less than the non-cooperative tariff. The four-instrument cooperative outcome is a "long way" in the values of the instruments from the two-instrument outcome shown in row 5 of Table 2. Yet the welfare gains to the four-instrument bargain are not a great deal larger than the twoinstrument case, a point I will return to in a minute.

In order to see the importance of the disagreement outcome to the cooperative solution, row 7 of Table 2 gives the results of a computation in which no intervention is the disagreement outcome with all four instruments endogenous. This is equivalent to maximizing the Cobb-Douglas product of the two countries' utilities. Note that this is very different from row 6 which uses the non-cooperative outcome as the disagreement outcome in bargaining. In row 7 , country n gives up its tariff entirely, while country s gets a small tariff to help raise its welfare. The difference between rows 6 and 7 in Table 2 is due to the big gain that country $n$ gets in the non-cooperative case by being able to turn the terms-oftrade substantially in its favor through a large tariff (1.567). This high level of welfare in the non-cooperative case then allows it to extract more in the bargaining solution in row 6 than if no intervention is the disagreement outcome. Country s is much better off with no intervention as the disagreement outcome, while country $n$ is worse off even relative to the non-cooperative Nash outcome. Quantitatively, the assumption of what is the disagreement outcome matters a lot.

It is interesting to see, in both Table 1 and Table 2, that cooperative bargaining does not extract much in the way of additional gains. The non-cooperative outcomes do a "good job" of extracting gains, since the non-internalized pollution externality is a positive spillover between countries. But this remains true in Table 2, even though the non-cooperative outcome has a big tariff for country h, which has a negative effect on country s. Apparently country s gets a sufficient benefit from n's pollution tax and from s's own tariff to much more than compensate. I have no reason to believe that this specific result has great generality beyond this specific case and I do not attach too much significance to the particular numerical values we are getting here. It clearly is the case that (a) the values of the instruments vary widely depending on what is bargained over and (b) both welfare and the instruments are very sensitive to the disagreement option.

The final exercise considers "policy leakage”, a term I will use to indicate one country reducing its abatement effort in response to an increase in its trading partner's abatement effort. There is no particular role for differences in per-capita income here, but I thought a couple of brief comments are worthwhile having developed the model. Most literature that I am aware deals with leakage through changes in market prices when one country imposes a carbon tax, for example, and the other country is (countries are) passive. Action by the first country lowers world fossil fuel prices and so firms and consumers in the passive country will use more.

This traditional mechanism doesn't work here by virtue of the fact that there is no 
carbon-intensive sector and hence no relative price change lowering fossil fuel prices in response to one country's tax. But we can get a policy response by the second country. A computational example is shown in Figure 6, where the horizontal axis is the (exogenous) level of country n's abatement tax. As we would expect, country s's option tax is negatively related to country n's tax as shown: the tax rates are "strategic substitutes" even though country s's welfare is increase in n's tax. A higher tax in n improves the environment and lowers the willingness to pay in country s. This is nothing other than a free-rider problem in environmental policy.

The marginal leakage rate can be defined in a few different ways. In Figure 6, it is defined as one minus the change in actual abatement when country s adjusts its tax optimally divided by the change in abatement that occurs when country s's tax is fixed, in response to a tax increase by country $n$. Thus if the increase in abatement by $n$ is perfectly offset by a decrease in abatement by country s, then the leakage rate is 1 . If country s does not adjust its tax, the leakage rate is zero. Under this definition, the leakage rate is high until country s's tax rate is driven to zero.

\section{Summary and Conclusions}

The purpose of the paper is to make the case that per-capita income has an interesting role to play in cooperative and non-cooperative international trade policy. While some of the results are not surprising, there are a number of interesting subtleties than may have gone unnoticed.

The model can inform policy and perhaps help us understand how we got to where we are. On the former, there has been much debate about linking issues in negotiations, and much of it has been ideological in nature: in high-income countries, the left thinks its great, the right thinks its awful. This paper suggests that linking can extract additional gains: recall that there are no gains to be had negotiating over environmental policy alone in our example.

In the area of understanding how we got to where we are, the results here may help explain why the high-income countries often seem to give up more than they get in international negotiations (some will surely dispute this assertion), such as the Kyoto Protocol. While this may indeed be all or in part due to simple altruism, some of our simulation results here suggest that this is also predicted by standard economic theories of cooperative and non-cooperative behavior. Specifically, with environmental quality a highincome-elasticity good, standard theory predicts a high abatement effort by high income countries, no need to appeal to altruism.

Some results make provide food for further thought and discussion. The point about the quantitative importance of the disagreement outcome is interesting. If the current status quo point is given legitimacy, then an initially highly-protected, free-riding country is going to do well in negotiations. If the current status quo point in not granted legitimacy then the bargaining outcome can be very different. For example, some rule that if bargaining fails then the outlier country faces sanctions changes the disagreement outcome and therefore the bargaining outcome. That of course opens the pandora's box of negotiating over what is going to be negotiated, something I'll leave to better theorists than myself. 
Appendix 1

First, the algebra on the CET transformation function, the national product function and the supply functions. I derive the unit national product function: the revenue derived from one unit of labor input into production.

$$
\begin{aligned}
& \underset{x}{\operatorname{Max}} \sum p_{i} x_{i}+\lambda\left[\left(\sum_{i} \alpha_{i}\left(\frac{x_{i}}{\alpha_{i}}\right)^{\beta}\right)^{\frac{1}{\beta}}-1\right] \\
& \frac{\partial L}{\partial X_{i}}=p_{i}-\lambda \frac{1}{\beta}\left(\sum_{i} \alpha_{i}\left(\frac{x_{i}}{\alpha_{i}}\right)^{\beta}\right)^{\frac{1}{\beta}-1} \alpha_{i} \beta\left(\frac{x_{i}}{\alpha_{i}}\right)^{\beta-1} \frac{1}{\alpha}=0 \\
& \frac{p_{j}}{p_{i}}=\left(\frac{x_{i} / \alpha_{i}}{x_{j} / \alpha_{j}}\right)^{\beta-1} \frac{x_{j}}{\alpha_{j}}=\left(\frac{p_{j}}{p_{i}}\right)^{\frac{1}{\beta-1}} \frac{x_{i}}{\alpha_{i}}=\left(\frac{p_{j}}{p_{i}}\right)^{\sigma} \frac{x_{i}}{\alpha_{i}} \\
& p_{j} x_{j}=\alpha_{j} p_{j}^{\sigma+1} p_{i}^{-\sigma} x_{i} / \alpha_{i} \\
& r(p)=\sum p_{j} x_{j}=\left(\sum \alpha_{j} p_{j}^{\sigma+1}\right) p_{i}^{-\sigma} \frac{x_{i}}{\alpha_{i}}
\end{aligned}
$$

Inverting this gives unit supply functions: the optimal output of each good for one unit of labor input into production.

$$
\begin{gathered}
x_{i}=\alpha_{i} p_{i}^{\sigma}\left(\sum \alpha_{j} p_{j}^{\sigma+1}\right)^{-1} r(p) \\
\alpha_{i}\left(\frac{x_{i}}{\alpha_{i}}\right)^{\frac{\sigma+1}{\sigma}}=\alpha_{i} p_{i}^{\sigma+1}\left(\sum \alpha_{j} p_{j}^{\sigma+1}\right)^{-\frac{\sigma+1}{\sigma}} r(p)^{\frac{\sigma+1}{\sigma}} \\
\sum \alpha_{i}\left(\frac{x_{i}}{\alpha_{i}}\right)^{\frac{\sigma+1}{\sigma}}=\sum\left(\alpha_{i} p_{i}^{\sigma+1}\right)\left(\sum \alpha_{j} p_{j}^{\sigma+1}\right)^{-\frac{\sigma+1}{\sigma}} r(p)^{\frac{\sigma+1}{\sigma}}=\left(\sum \alpha_{i} p_{i}^{\sigma+1}\right)^{-\frac{1}{\sigma}} r(p)^{\frac{\sigma+1}{\sigma}} \\
\left(\sum \alpha_{i}\left(\frac{x_{i}}{\alpha_{i}}\right)^{\frac{\sigma+1}{\sigma}}\right)^{\frac{\sigma}{\sigma+1}}=1=\left(\sum \alpha_{i} p_{i}^{\sigma+1}\right)^{-\frac{1}{\sigma+1}} r(p)
\end{gathered}
$$

This gives us the unit national product function, which could also be termed the producer price index in an analogy to the CES consumer price index so widely used in 
monopolistic competition and economic geography.

$$
r(p)=\left(\sum \alpha_{i} p_{i}^{\sigma+1}\right)^{\frac{1}{\sigma+1}}=p_{z}
$$

The unit national product function or producer price index is also CET, a self-dual prorerty familiar from the CES demand literature. Substitute this into the supply functions above.

$$
x_{i}=\alpha_{i} p_{i}^{\sigma}\left(\sum \alpha_{j} p_{j}^{\sigma+1}\right)^{-1}\left(\sum \alpha_{i} p_{i}^{\sigma+1}\right)^{\frac{1}{\sigma+1}}=\alpha_{i} p_{i}^{\sigma}\left(\sum \alpha_{j} p_{j}^{\sigma+1}\right)^{-\frac{\sigma}{\sigma+1}}
$$

This gives us more compact unit and total supply functions.

$$
x_{i}=\alpha_{i} p_{i}^{\sigma} r(p)^{-\sigma} \quad X_{i}=\alpha_{i} p_{i}^{\sigma} r(p)^{-\sigma} L_{z}
$$

Second, the algebra for the terms-of-trade effect under the special assumptions noted in the text.

$$
\begin{aligned}
& \frac{X_{1}^{n}+X_{1}^{s}}{X_{2}^{n}+X_{2}^{s}}=\frac{\alpha_{1}^{n} L_{z}^{n}+\alpha_{1}^{s} L_{z}^{s}}{\alpha_{2}^{n} L_{z}^{n}+\alpha_{2}^{s} L_{z}^{s}}=\frac{p_{2}}{p_{1}} \\
& \frac{\left(\alpha_{2}^{n} L_{z}^{n}+\alpha_{2}^{s} L_{z}^{s}\right) \alpha_{1}^{n}-\left(\alpha_{1}^{n} L_{z}^{n}+\alpha_{1}^{s} L_{z}^{s}\right) \alpha_{2}^{n}}{\left(\alpha_{2}^{n} L_{z}^{n}+\alpha_{2}^{s} L_{z}^{s}\right)^{2}} d L_{z}^{n}=d\left(p_{2} / p_{1}\right)
\end{aligned}
$$

Assume that the countries are identical initially and that there are no initial abatement taxes, so that $L_{z}^{n}=L_{z}^{s}=L_{z}$ where $L_{z}$ is the total endowment of each country. Second, assume symmetry in the comparative advantage parameters such that $\alpha_{1}^{n}=\alpha_{2}^{s}=\left(1-\alpha_{2}^{n}\right)=\left(1-\alpha_{1}^{s}\right)$. Then (xx) can be simplified to

$$
\frac{\left(\alpha_{1}^{n 2}-\alpha_{2}^{n 2}\right) L_{z}^{n} L_{z}^{s}}{\left(\alpha_{1}^{n}+\alpha_{2}^{n}\right)^{2} L_{z}^{s^{2}}} \frac{d L_{z}^{n}}{L_{z}^{n}}=d\left(p_{2} / p_{1}\right)
$$

Because $\alpha_{1}^{n}+\alpha_{2}^{n}=1$ and $p_{1} / p_{2}=1$ initially, this further simplifies to

$$
\left(\alpha_{1}^{n}-\alpha_{2}^{n}\right) \frac{d L_{z}^{n}}{L_{z}^{n}}=\frac{d\left(p_{2} / p_{1}\right)}{\left(p_{2} / p_{1}\right)} \quad \text { or } \quad \frac{d\left(p_{2} / p_{1}\right)}{\left(p_{2} / p_{1}\right)}=\left(\alpha_{1}^{n}-\alpha_{2}^{n}\right) \frac{d L_{z}^{n}}{L_{z}^{n}}
$$

The effect of country n withdrawing a unit of labor from production $\left(d L_{z}{ }^{n}<0\right)$ is to reduce the relative price of country s's export good (country s has a deterioration in its terms of trade) with the size of this effect being proportional to the size of comparative advantage spread. 
Appendix 2:

In this appendix, I briefly introduce the general idea of an MPEC problem, and show a simple example.

MPEC: mathematical programming with equilibrium constraints an MPEC is basically a:

NLP (non-linear programming): constrained optimization where the constraint set is an

MCP (mixed complementarity problem): an economic equilibrium problem consisting of a a set of weak inequalities each with a matched non-negative variable.

Here is a simple example of an MCP: simple supply-demand problem with two unknown, price (p) and quantity (x). First, solve the underlying producer and consumer optimization problems (themselves MPECs) to get

c'(x): the producer's marginal cost function and

$\mathrm{d}(\mathrm{p})$ : the consumer's demand function

The economic equilibrium problem should be specified as follow:

$c^{\prime}(x) \geq p \quad$ matched to $x \quad$ (if $c^{\prime}>p$, then the good is not produced $=>x=0$ )

$\mathrm{x} \geq \mathrm{d}(\mathrm{p}) \quad$ matched to $\mathrm{p}$ (if $\mathrm{x}>\mathrm{d}(\mathrm{p})$, then $\mathrm{x}$ is a free good $=>\mathrm{p}=0$ )

$\mathrm{x}, \mathrm{p} \geq 0$

One technique is to add two non-negative "slack" variables to convert the first two inequalities to four equalities. Let subscript $m$ denote market and subscript $\mathrm{p}$ denote pricing or profits. The four-equation system is:

$$
\begin{array}{ll}
\mathrm{s}_{\mathrm{m}}=\mathrm{x}-\mathrm{d}(\mathrm{p}) & \mathrm{s}_{\mathrm{m}} \text { : measure of excess supply in equilibrium } \\
\mathrm{s}_{\mathrm{p}}=\mathrm{c}^{\prime}(\mathrm{x})-\mathrm{p} & \mathrm{s}_{\mathrm{p}} \text { : measure of unprofitability in equilibrium } \\
\mathrm{s}_{\mathrm{m}} \mathrm{P}=0 & \\
\mathrm{~s}_{\mathrm{p}} \mathrm{x}=0 & \mathrm{~s}_{\mathrm{p}}, \mathrm{s}_{\mathrm{m}}, \mathrm{x}, \mathrm{p} \geq 0
\end{array}
$$

The importance of matching inequalities and variables can be seen by the fact that this simple MCP has one of three possible solutions.
(1) $\mathrm{s}_{\mathrm{m}}=\mathrm{s}_{\mathrm{p}}=0$, $\mathrm{x}$ and $\mathrm{p}>0$
interior solution
(2) $\mathrm{s}_{\mathrm{m}}=0, \mathrm{~s}_{\mathrm{p}}>0, \mathrm{x}=0, \mathrm{p}>0$
technology too costly, not used
(3) $\mathrm{s}_{\mathrm{m}}>0, \mathrm{~s}_{\mathrm{p}}=0, \mathrm{x}>0, \mathrm{p}=0$
$\mathrm{x}$ is a free good 
Figure 1A shows the three possible outcomes of the supply-demand problem. Case 2 comes up a lot in economic modeling. One example would be production of electricity, where there are multiple technologies to produce electricity. Some technologies will be unprofitable and will not be used in equilibrium. A second example occurs in international trade models, where many trade linking are slack (not used), since they are unprofitable.

Case 3 is somewhat less common. It can occur in trade models, for example, when there are fixed input coefficients in production (Leontief technologies). Then if one factor of production is in sufficiently plentiful supply, its price will be zero in equilibrium.

Here is an example of an MPEC in our simple problem. Suppose that the government wants to set a tax $t$ in this market to maximize tax revenue. Let $\mathrm{p}$ be the consumer price of $\mathrm{x}$, so $c^{\prime}(\mathrm{x})=\mathrm{p} /(1+\mathrm{t})$ is the producer price. and the producer price is the tax base.

\section{MPEC:}

maximize wrt to t: $\quad$ taxrev $=c^{\prime}(x) t x$

subject to the economic equilibrium problem (MCP):

$$
\begin{array}{lll}
c^{\prime}(\mathrm{x})(1+\mathrm{t}) \geq \mathrm{p} & \perp & \mathrm{x} \\
\mathrm{x} \geq \mathrm{d}(\mathrm{p}) & \perp & \mathrm{p} \\
\mathrm{x}, \mathrm{p} \geq 0 & &
\end{array}
$$

Suppose our good is electricity produced by solar cells, but they are unprofitable in equilibrium (case 2). What is the subsidy rate $s$, on marginal cost, that will get the industry to produce $\mathrm{x}=1$ units of electricity with this technology?

MPEC

minimize wrt to s: $\quad$ subsidy payments $=c^{\prime}(x) s x$

subject to the economic equilibrium problem (MCP) and auxiliary constraint:

$$
\begin{array}{lll}
c^{\prime}(\mathrm{x})(1-\mathrm{s}) \geq \mathrm{p} & \perp & \mathrm{x} \\
\mathrm{x} \geq \mathrm{d}(\mathrm{p}) & \perp & \mathrm{p} \\
\mathrm{x} \geq 1 & & \\
\mathrm{x}, \mathrm{p} \geq 0 &
\end{array}
$$

where $\mathrm{x} \geq 1$ is an additional unmatched constraint. If the technology is profitable without the subsidy and $x>1$ with no subsidy (case 1 ), this program will return the solution $s=0$. If $s$ is specified as a free variable (may take a negative value) then, in this case, the program will return an $\mathrm{s}<0$ (tax revenue) that achieves $\mathrm{x}=1$. 


\section{REFERENCES}

Abrego, Lisandro, Carlo Perroni, John Whalley, and Randall M.Wigle (2001), “Trade and Environment:Bargaining Outcomes from Linked Negotiations,” Review of International Economics 9, 414-28.

Bagwell, Kyle and Robert Staiger (2001), "Domestic Policies, National Sovereignty and International Economic Institutions,” Quarterly Journal of Economics 116, 519-62.

Broner, Fernando A., Paula Bustos and Vasco M. Carvalho (2012), "Sources of Comparative Advantage in Polluting Industries”, CEPR discussion paper 9111.

Caron, Justin, Thibault Fally and James R. Markusen (2012), “Skill Premium and Trade Puzzles: a Solution Linking Production and Preferences”, working paper.

Chiu, Yi-Bin (2012), “Deforestation and the Environmental Kuznets Curve in Developing Countries: A Panel Smooth Transition Regression Approach”, Canadian Journal of Economics 60, 177-194.

Conconi, Paola and Carlo Perroni (2002), "Issue Linkage and Issue Tie-In in Multilateral Negotiations,” Journal of International Economics 57, 423-47.

Copeland, Brian R. and M. Scott Taylor (1994), "North-South Trade and the Environment”, Quarterly Journal of Economics 109, 755-787.

Copeland, Brian R. and M. Scott Taylor (2004), “Trade, growth, and the environment”, Journal of Economic Literature 42, 7-71.

Copeland, Brian R. and M. Scott Taylor (2005), "Free trade and Global Warming: a TradeTheory View of the Kyoto Protocol”, Journal of Environmental Economics and Management 49, 205-234.

Grossman, Gene M., and Alan B. Krueger (1995), “Economic Growth and the Environment”, Quarterly Journal of Economics 110, 353-377.

Harstad, Bård (2012), “Buy Coal! A Case for Supply-Side Environmental Policy”, Journal of Political Economy 120, 77-115.

Horstmann, Ignatius J., James R. Markusen and Jack Robles (2005), "Multi-issue Bargaining and Linked Agendas: Ricardo Revisited or No Pain No Gain”, Review of International Economics 13, 185-204.

Hunter, Linda (1991), “The Contribution of Non-homothetic Preferences to Trade”, Journal of International Economics 30, 345-358.

Hunter, Linda and James R. Markusen (1988), "Per-Capita Income as a Determinant of Trade," in Robert Feenstra (editor), Empirical Methods for International Economics, Cambridge: MIT Press 89-109. 
Kuznets, Simon (1966), Modern Economic Growth: Rate, Structure and Spread, Yale University Press.

Lovei, Magda (1998), "Phasing out Lead from Gasoline: Worldwide experience and Policy Implications”, World Bank Technical Paper No. 397.

Markusen, James R. (1975), "Cooperative Control of International Pollution and Common Property Resources," Quarterly Journal of Economics 89, 618-632.

Markusen, James R. (1986). "Explaining the Volume of Trade: An Eclectic Approach." American Economic Review 76, 1002-1011.

Markusen, James R., Edward Morey and Nancy Olewiler (1995), "Competition in Regional Environmental Policies with Endogenous Plant Location Decisions", Journal of Public Economics 56, 55-77.

Markusen, James R., and Randall Wigle (1989), "Nash Equilibrium Tariffs for the U.S. Canada: The Roles of Country Size, Scale Economies, and Capital Mobility”, Journal of Political Economy 97, 368-386.

Selden, T.M., and D.Q. Song (1994), "Environmental Quality and Development - Is there a Kurznets Curve for Air-Pollution Emissions”, Journal of Environmental Economics and Management 27, 147-162.

Spagnolo, G. (2000), “Issue Linkage, Delegation, and International Policy Cooperation,” manuscript.

Tang, John (2012), 'Pollution Havens and the Trade in Toxic Chemicals: Evidence from U.S. Trade Flows”, Australian National University working paper.

World Bank (2011), http://data.worldbank.org/indicator/NY.GDP.PCAP.PP.CD?page=3 
Plot 1: Maximum lead content of gasoline (petrol) in relation to log GDP per-capita at PPP: regression line: $y=\alpha+\beta \ln (x)$

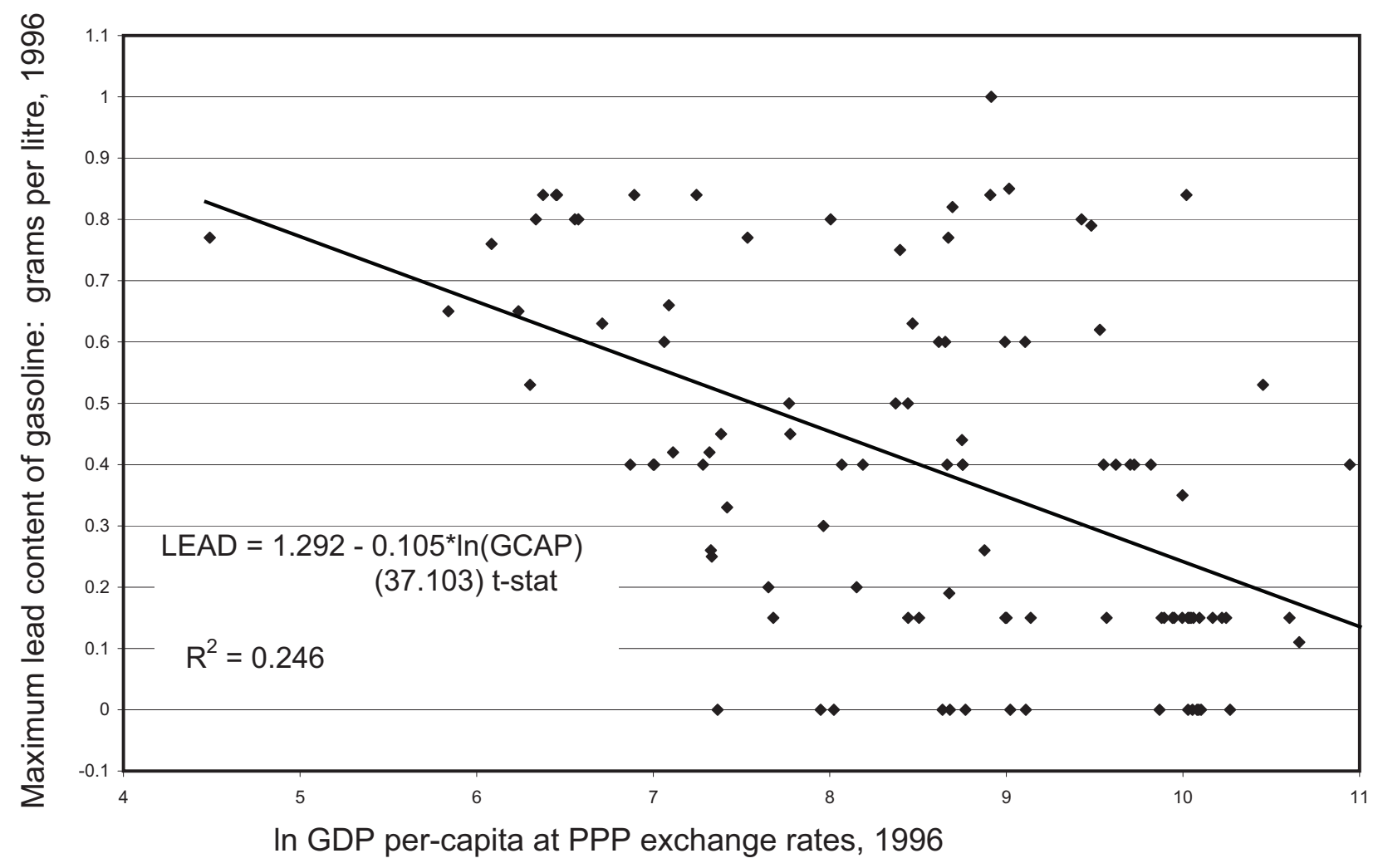


TABLE 1: Welfare and abatement taxes under alternative secnarios

\begin{tabular}{|c|c|c|c|c|c|c|}
\hline & \multicolumn{2}{|c|}{$\begin{array}{l}\text { Base case: n's per-capita } \\
\text { income } 1.5 \text { that of country s }\end{array}$} & \multicolumn{2}{|c|}{$\begin{array}{l}\text { Alternative case } 1: \text { no } \\
\text { comparative advantage }\end{array}$} & \multicolumn{2}{|c|}{$\begin{array}{l}\text { Alternative case } 2 \text { : n's } \\
\text { per-capita income } \\
9 \text { times that of } s\end{array}$} \\
\hline & Welfare $n$ & Welfare s & Welfare $n$ & Welfare s & Welfare $\mathrm{n}$ & Welfare s \\
\hline PTAX = 0 & 1.000 & 1.000 & 1.000 & 1.000 & 1.000 & 1.000 \\
\hline Non-cooperative NE & 1.207 & 1.196 & 1.136 & 1.120 & 1.161 & 1.012 \\
\hline $\begin{array}{l}\text { Coop Nash } \\
\text { NE outside option }\end{array}$ & 1.237 & 1.217 & 1.197 & 1.255 & 1.161 & 1.012 \\
\hline $\begin{array}{l}\text { CD world welfare } \\
\text { index max* }\end{array}$ & 1.290 & 1.173 & 1.290 & 1.173 & 1.267 & 0.944 \\
\hline $\begin{array}{l}\text { Rawlsian world } \\
\text { welfare max }\end{array}$ & 1.225 & 1.225 & 1.237 & 1.228 & 1.160 & 1.012 \\
\hline TAX RATES & PTAXN & PTAXS & PTAXN & PTAXS & PTAXN & PTAXS \\
\hline Non-cooperative NE & 0.32 & 0.08 & 0.24 & 0.03 & 0.41 & 0 \\
\hline $\begin{array}{l}\text { Coop Nash } \\
\text { NE outside option }\end{array}$ & 0.51 & 0.21 & 0.51 & 0.22 & 0.41 & 0 \\
\hline $\begin{array}{l}\text { CD world welfare } \\
\text { index } \text { max }^{*}\end{array}$ & 0.35 & 0.35 & 0.35 & 0.35 & 0.22 & 0.22 \\
\hline $\begin{array}{l}\text { Rawlsian world } \\
\text { welfare max }\end{array}$ & 0.57 & 0.20 & 0.48 & 0.28 & 0.45 & 0 \\
\hline
\end{tabular}

${ }^{*}$ Cobb-Douglas index used is $\left(\right.$ WELN)^ $0.5^{*}(\text { WELFS })^{\wedge} 0.5$; welfare $n, s$ normalized to 1 at zero taxes

**Rawlsian welfare index is MIN(WELN, WELS); welfare $n, s$ normalized to 1 at zero taxes

TABLE 2: Welfare and abatement taxes under alternative linking secnarios

Country $\mathrm{n}$ has five times the total income and per-capita income of country $\mathrm{s}$

\begin{tabular}{|c|c|c|c|c|c|c|}
\hline & Welfare $n$ & Welfare s & PTAXN & PTAXS & TARN & TARS \\
\hline No intervention & 0.731 & 0.788 & 0 & 0 & 0 & 0 \\
\hline $\begin{array}{l}\text { Non-cooperative Nash } \\
\quad \text { each county coordinates tax and tariff }\end{array}$ & 1.000 & 1.000 & 0.386 & 0 & 1.567 & 0.196 \\
\hline $\begin{array}{c}\text { Cooperative Nash usin non-cooperative outc } \\
\text { as disagreement outcome }\end{array}$ & ome & & & & & \\
\hline Isolated environment negotiation & 1.000 & 1.000 & 0.386 & 0 & 1.567 & 0.196 \\
\hline Isolated tariff negotiation & 1.008 & 1.048 & 0.386 & 0 & 1.015 & 0 \\
\hline Bargain over TARN and PTAXS & 1.005 & 1.025 & 0.386 & 0.150 & 0.692 & 0.196 \\
\hline Bargain over all four instuments & 1.009 & 1.059 & 0.452 & 0.034 & 1.015 & 0 \\
\hline $\begin{array}{l}\text { Bargain over all four instruments } \\
\text { with transfer } \mathrm{s} \text { to } \mathrm{n}(=22.0 \% \text { of } \mathrm{s}\end{array}$ & income) & 1.075 & 0.541 & 0 & 0 & 0 \\
\hline $\begin{array}{c}\text { Cooperative Nash using no intervention } \\
\text { as disagreement outcome }\end{array}$ & $\begin{array}{l}\text { ( now normalized } \\
\text { intervention }=1 \text { ) }\end{array}$ & & & & & \\
\hline Isolated environment negotiation & 0.945 & 1.306 & 0.631 & 0 & 0 & 0 \\
\hline Isolated tariff negotiation & 0.731 & 0.788 & 0 & 0 & 0 & 0 \\
\hline Bargain over TARN and PTAXS & 0.785 & 0.792 & 0 & 0.126 & 0 & 0 \\
\hline Bargain over all four instuments & 0.943 & 1.310 & 0.628 & 0 & 0 & 0.048 \\
\hline $\begin{array}{l}\text { Bargain over all four instruments } \\
\text { with transfer } \mathrm{s} \text { to } \mathrm{n}(=-2.3 \% \text { of } \mathrm{s}\end{array}$ & income) & 1.333 & 0.621 & 0 & 0 & 0 \\
\hline
\end{tabular}


Figure 1a: Effect of abatement by country $n$ on the commodity consumption of both countries: no comparative advantage

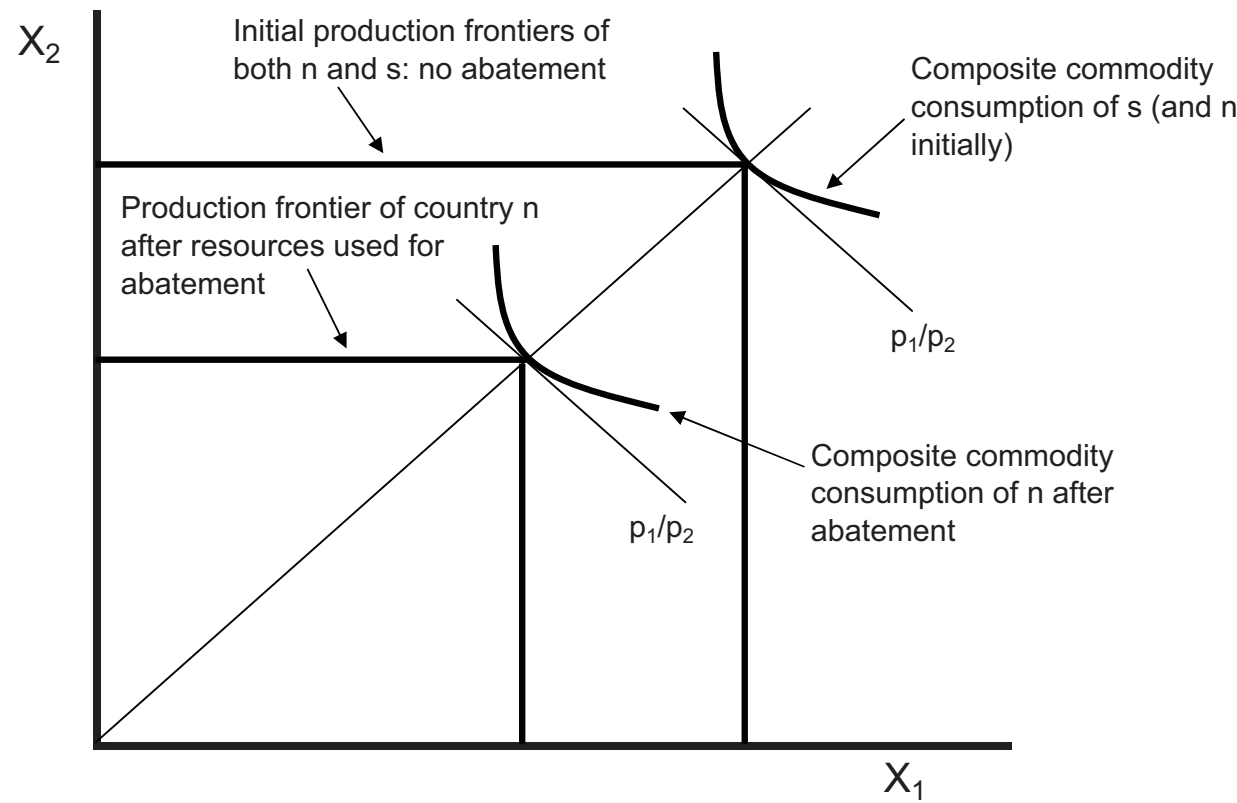

Figure 1b: Effect of abatement by country $n$ on the commodity consumption of both countries: complete specialization

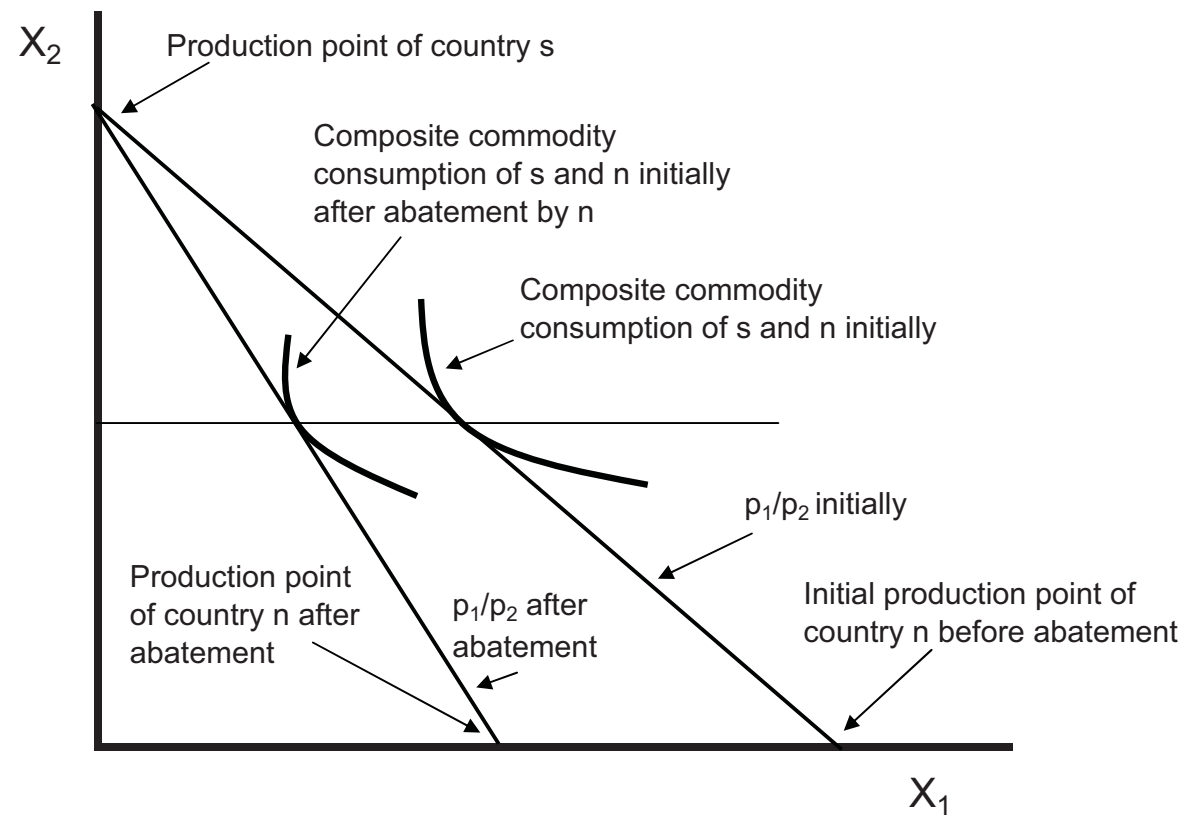


Figure 2: Welfare, environmental quality

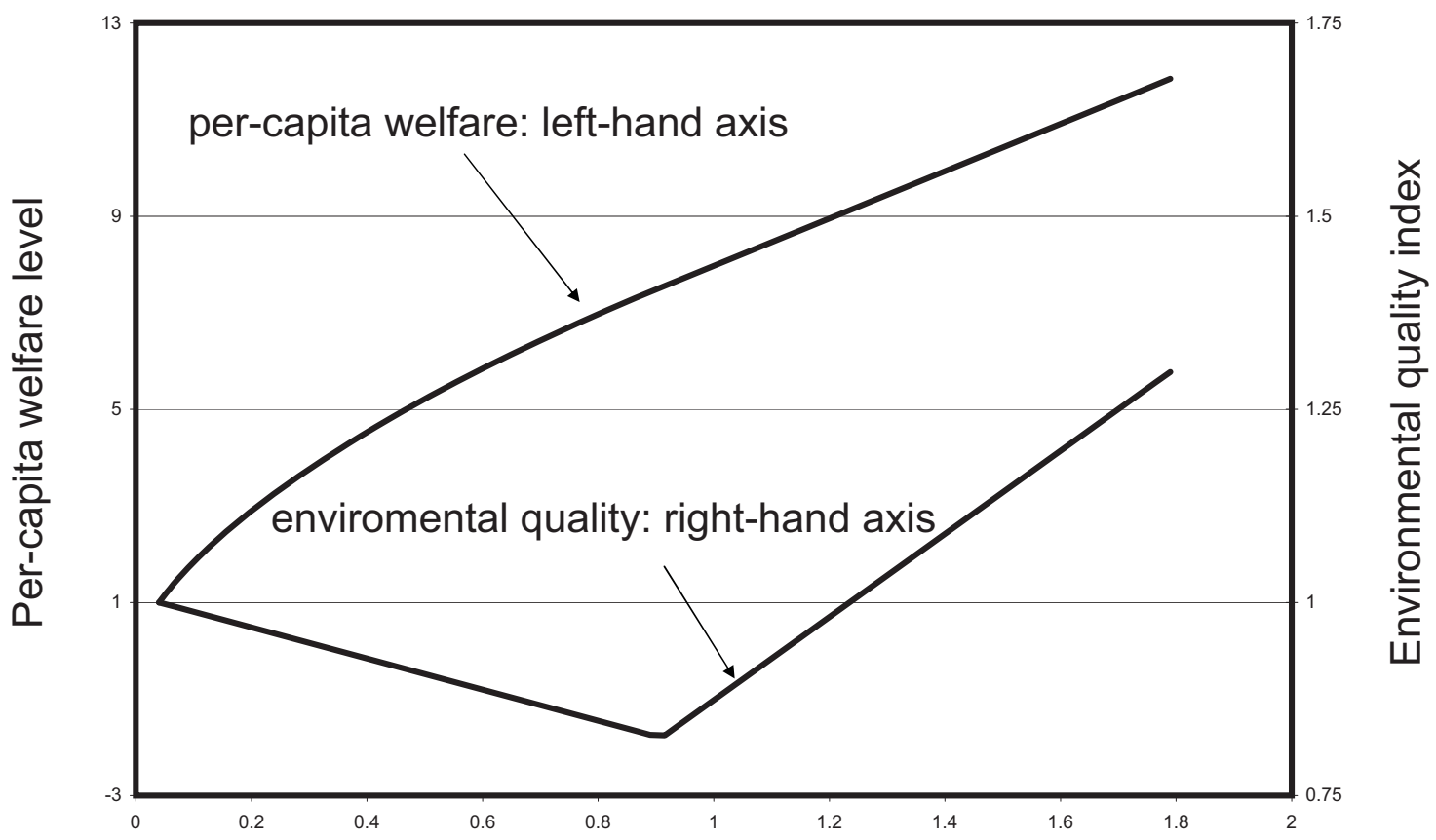

Per-capita income level

Figure 3: Effect of differing per capita income on equilibria

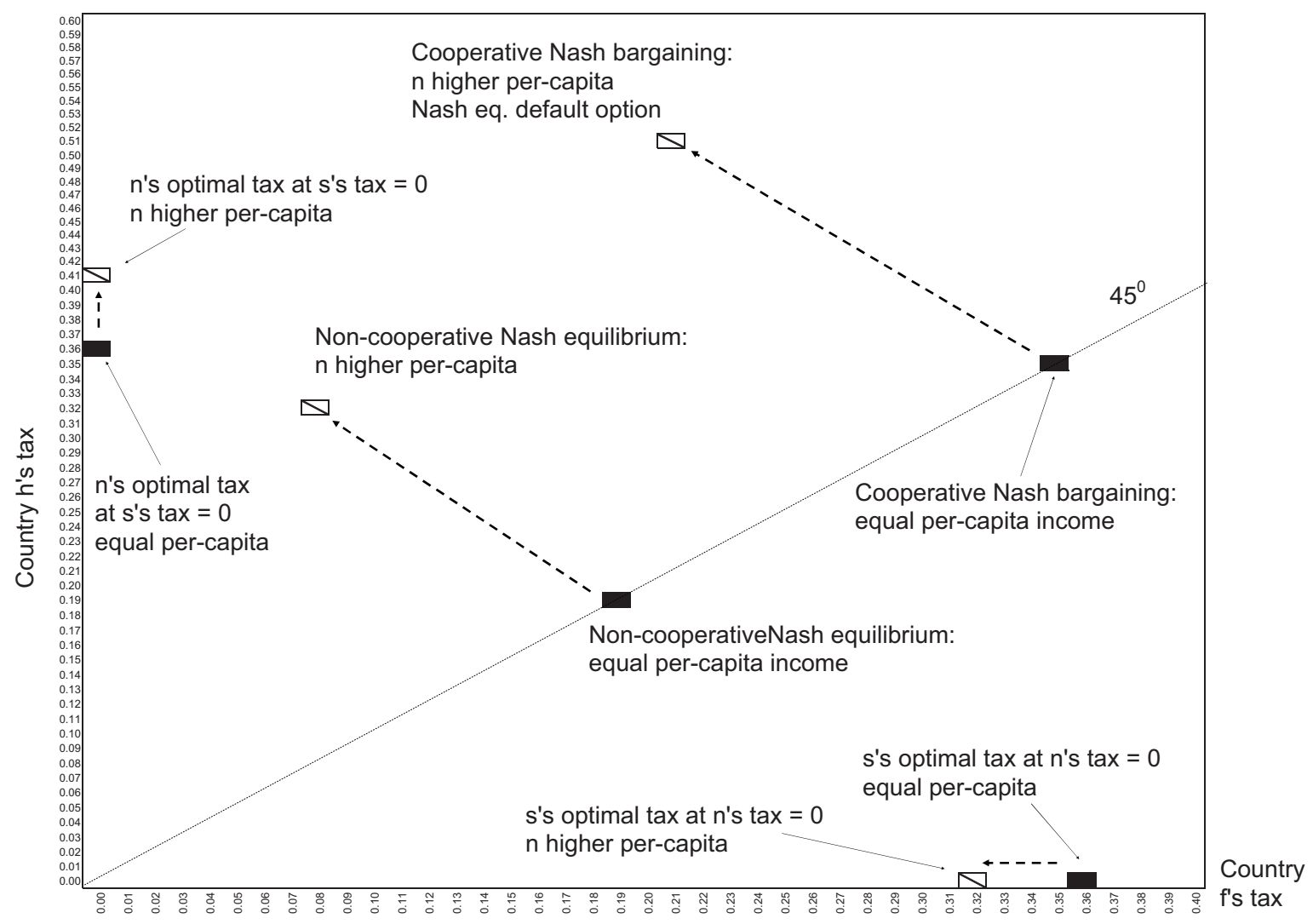


Figure 4: Infeasibility of an equal tax bargaining rule $\left(\operatorname{ptax}_{n}=\operatorname{ptax}_{\mathrm{s}}\right)$ when

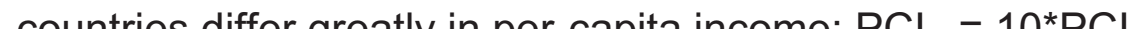

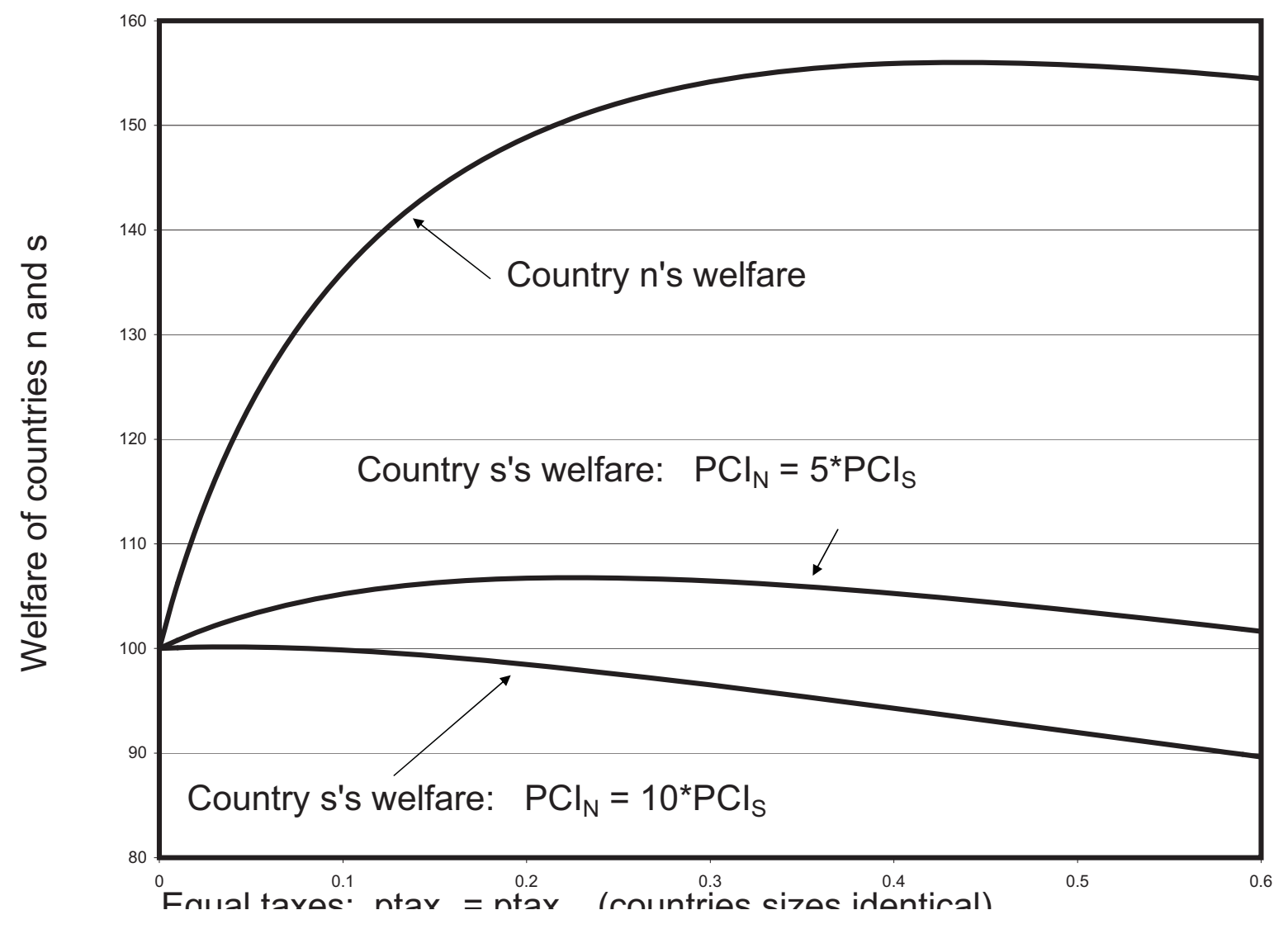

Figure 5: Gains from cooperative linked bargaining lower tarn traded for higher ptaxs

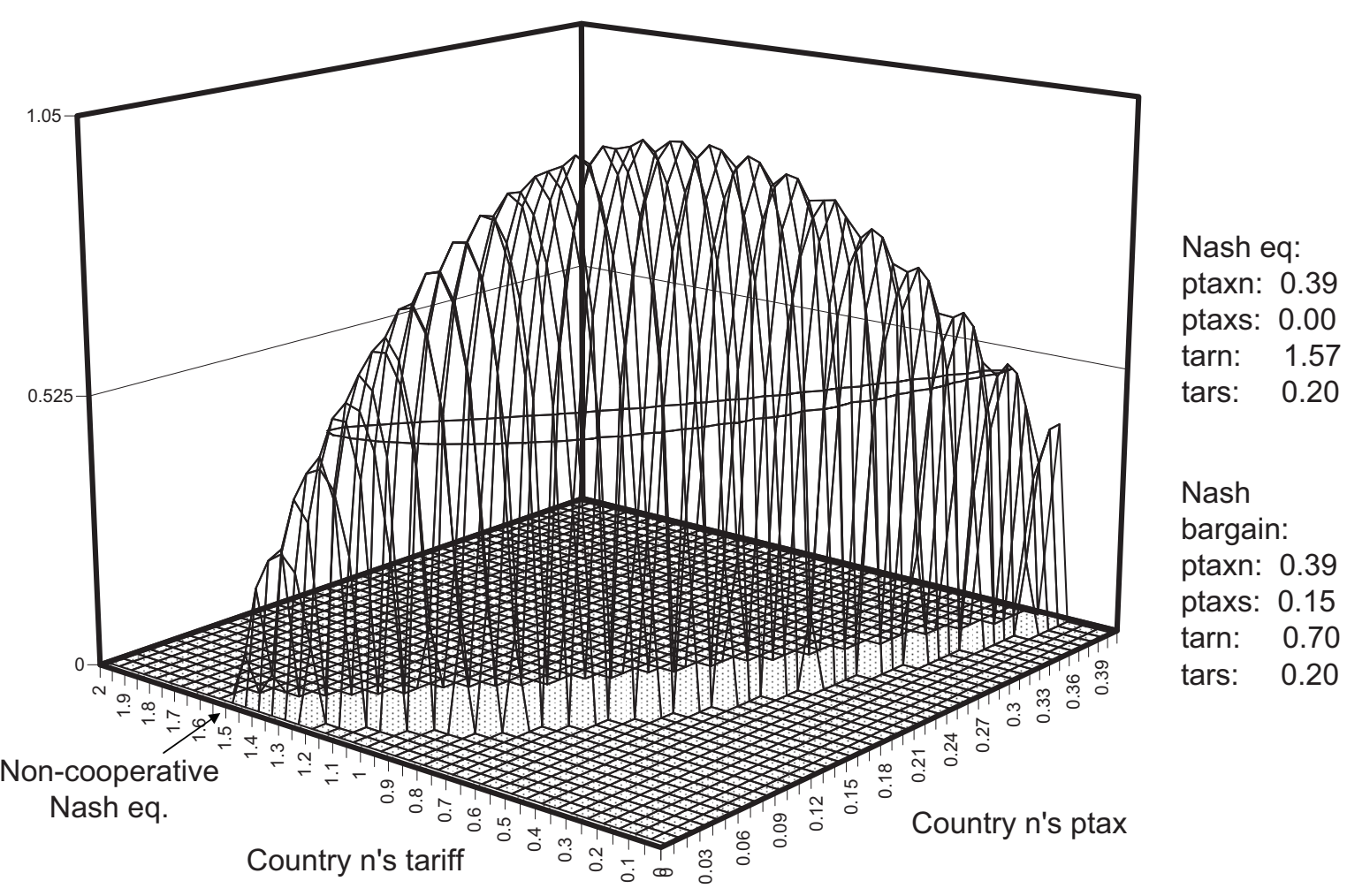


Figure 6: Illustration of "policy leakage": country s makes a best response to country n's (exogenous) tax

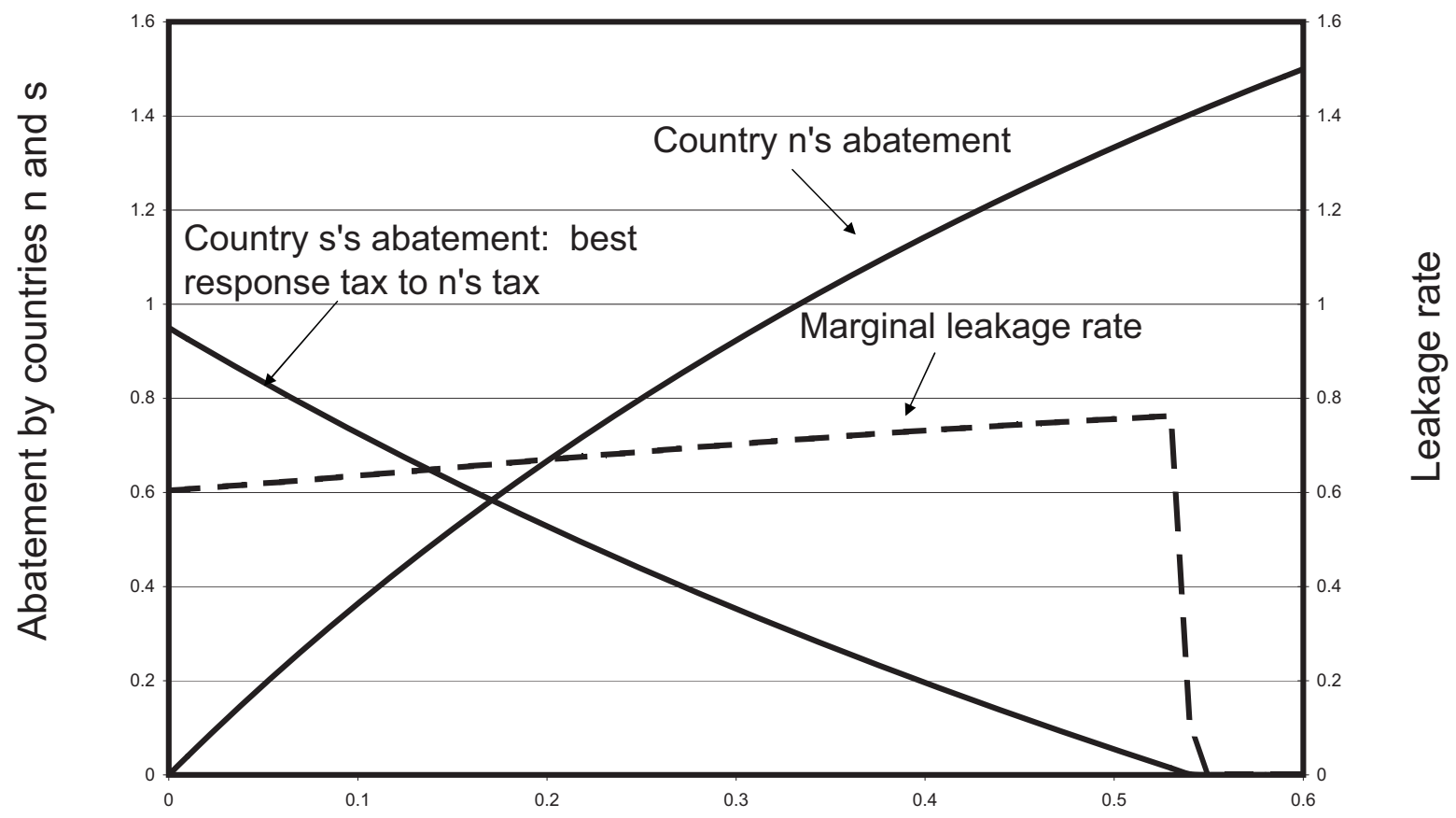

Country n's tax rate

Figure A1: Three outcomes of the mcp example

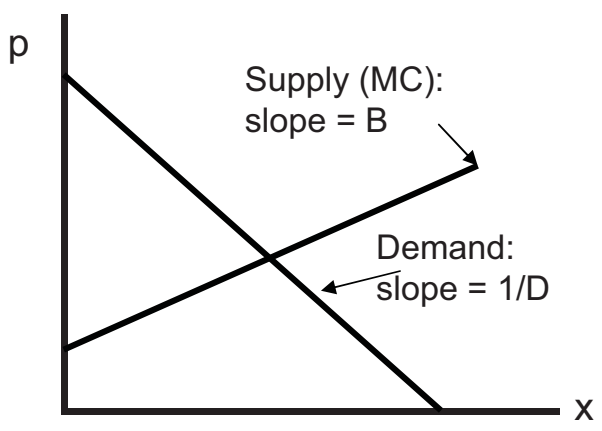

Case 1: interior solution

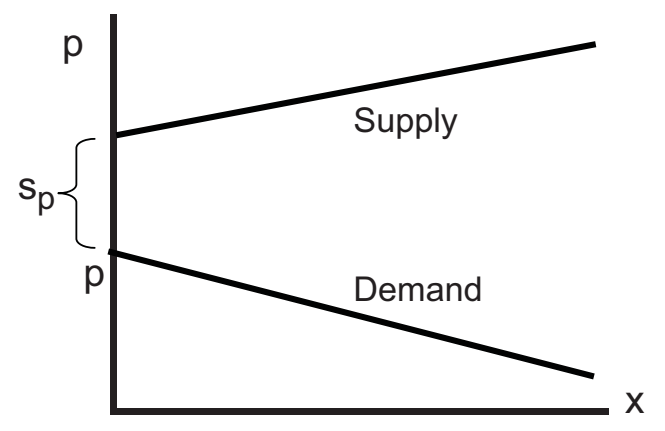

Case 2: $\mathrm{x}$ is too expensive, not produce in equilibrium $(x=0)$

Case 3: excess supply, $x$ is a free good in equilibrium $(p=0)$

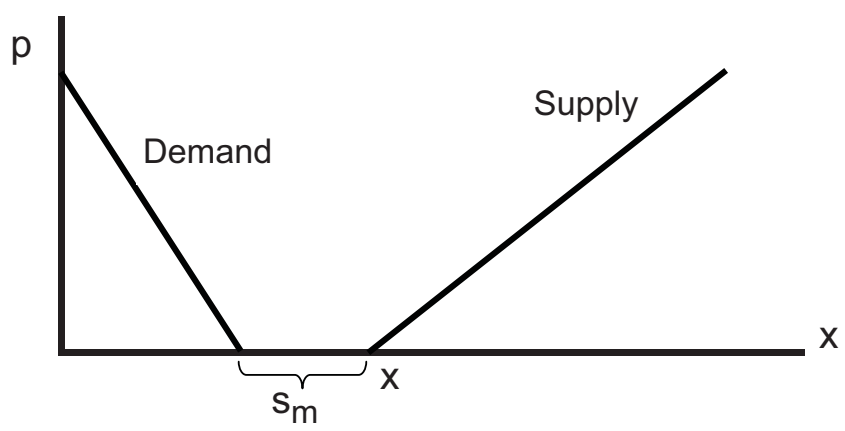




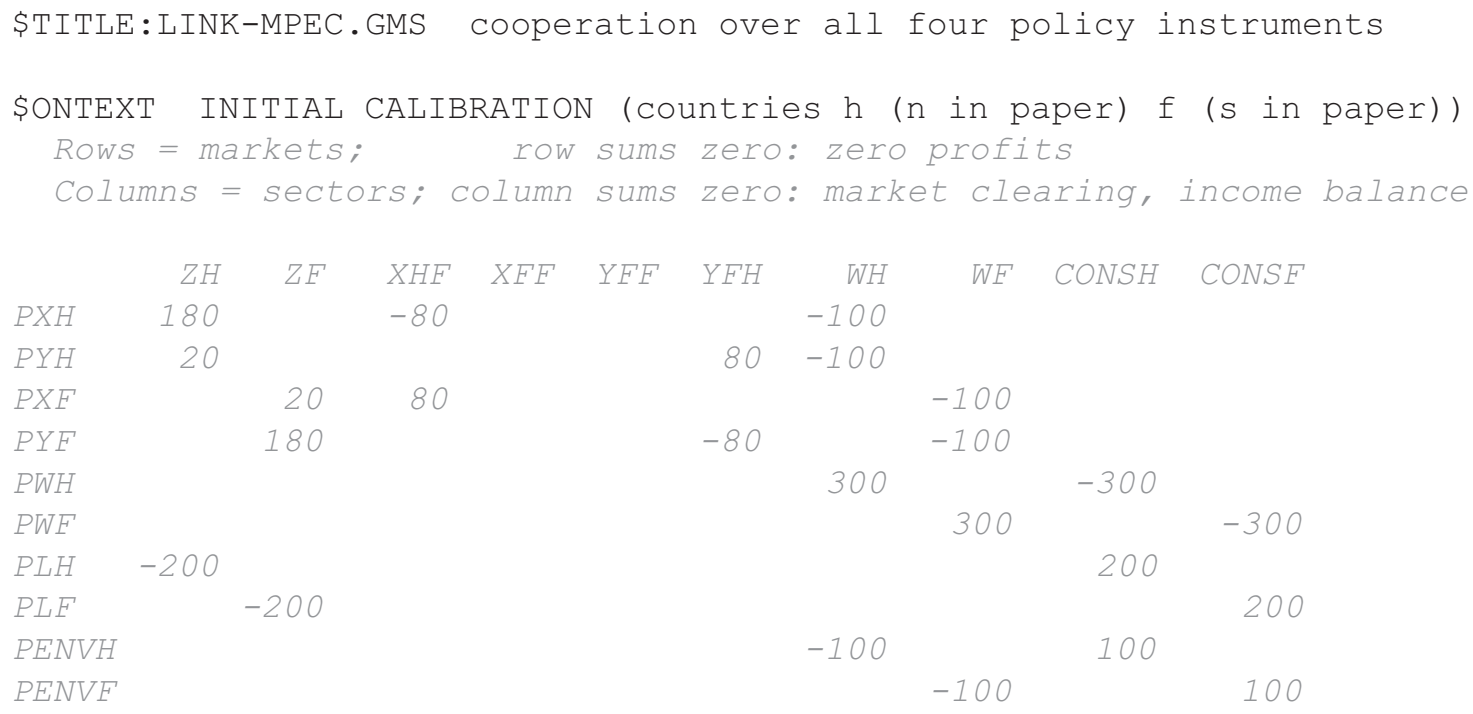

100 units of initial E endowment reduced by production (not shown) \$OFETEXT

\section{PARAMETERS}

VALH per-capita income paramater for the S-G preferences - $\mathrm{h}$

VALF per-capita income paramater for the S-G preferences - $f$

SIGMA elasticity of transformation between $\mathrm{X}$ and $\mathrm{Y}$

ENDOWLH factor endowment of country $h$

ENDOWLF factor endowment of country $f$

WELHN disagreement outcome for country h in bargaining

WELFN disagreement outcome for country f in bargaining;

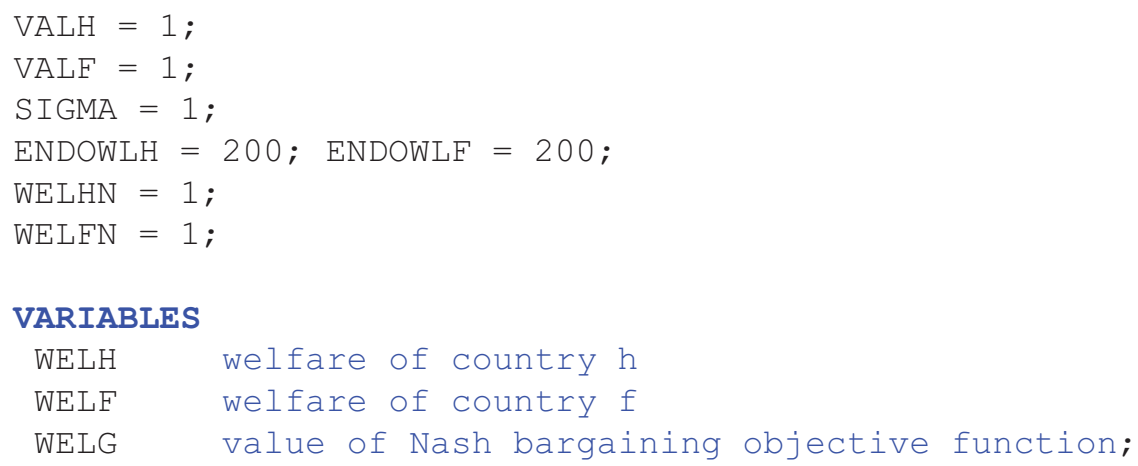

\section{VARIABLES}

WELH welfare of country h

WELF Welfare of country $f$

WELG value of Nash bargaining objective function;

\section{POSITIVE VARIABLES}

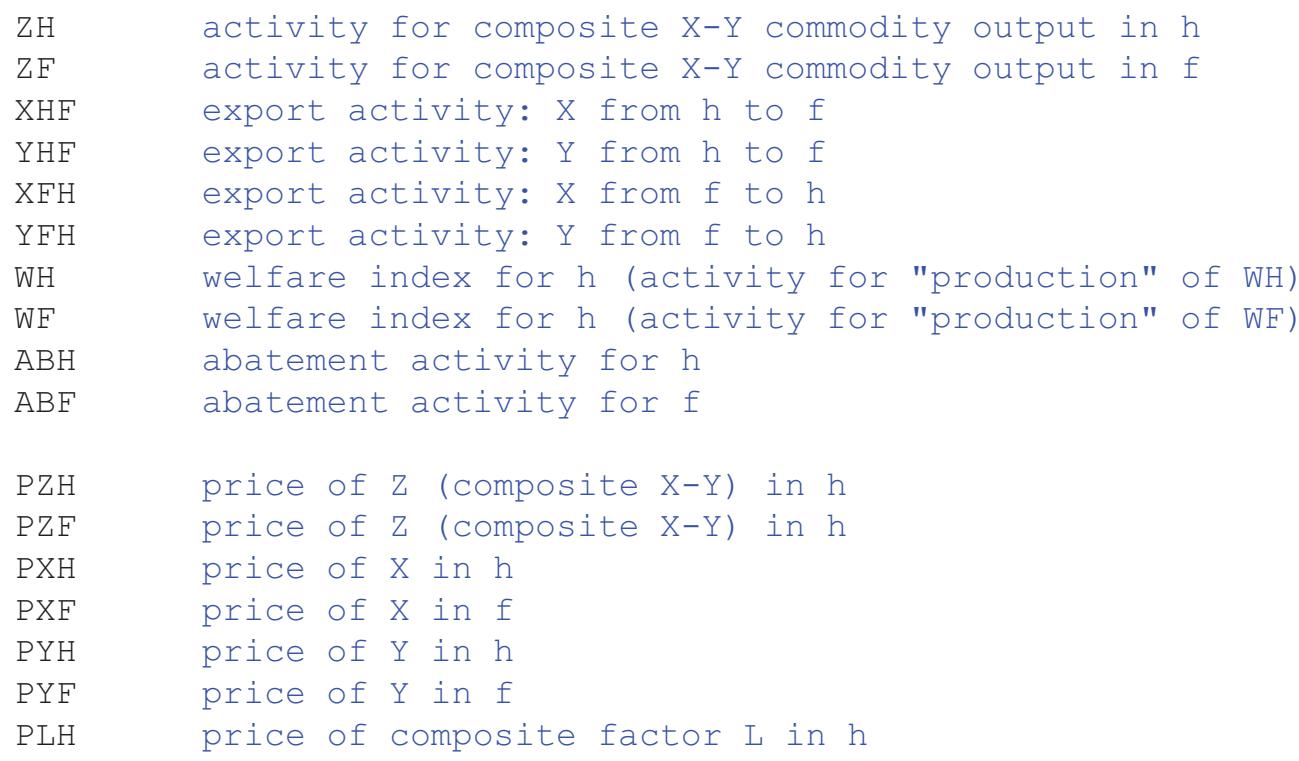




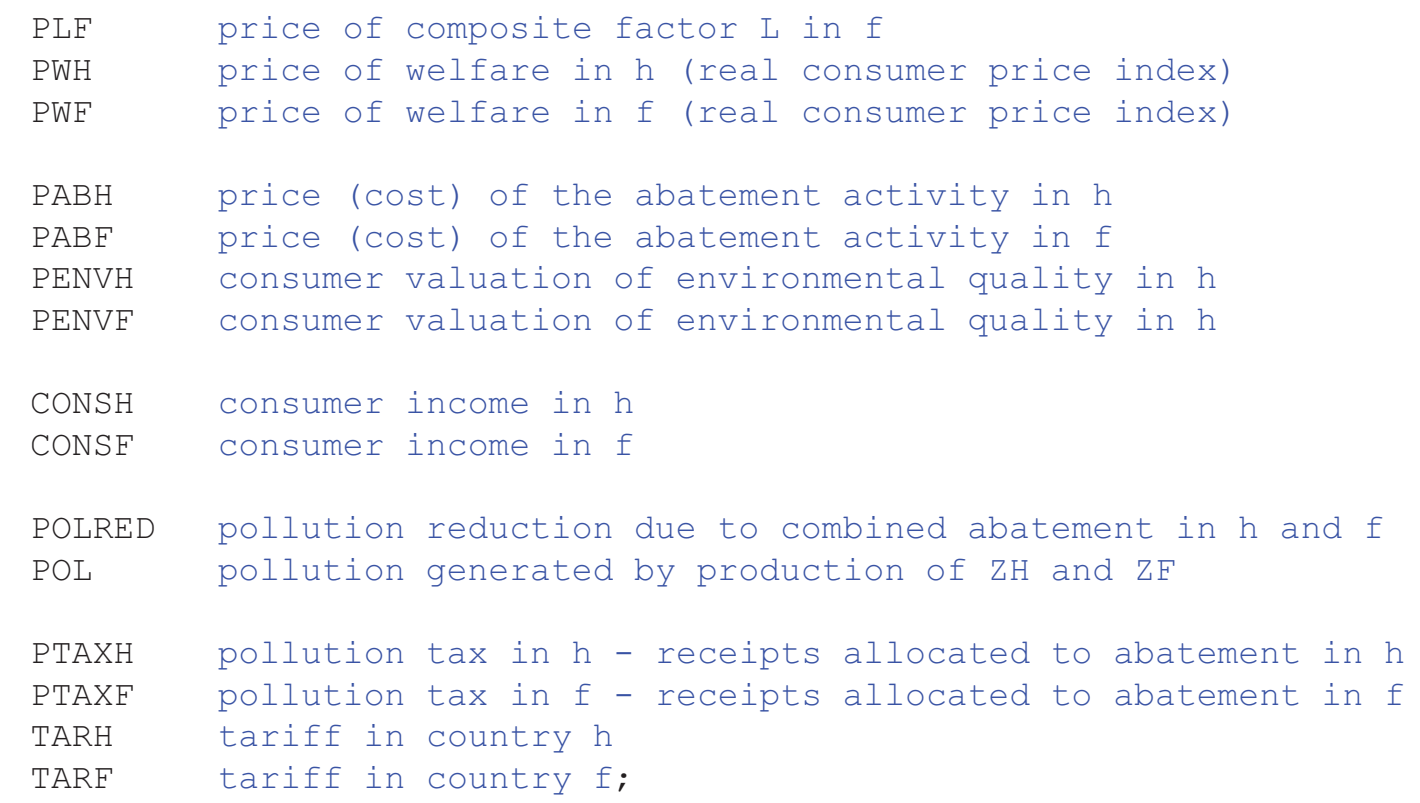

\section{EQUATIONS}

WELFAREH welfare of country h

WELFAREF welfare of country f

WELFAREG Nash bargaining objective function

\begin{tabular}{|c|c|c|c|c|c|c|c|c|}
\hline $\operatorname{costzH}$ & pricing equation & for $\mathrm{ZH}$ & $(\cos t=$ & $=\mathrm{G}=$ & price) & - comp & var ZH & \\
\hline OSTZF & pricing equation & for ZF & (cost $=$ & $=\mathrm{G}=$ & price) & - comp & var ZF & \\
\hline OSTXHF & pricing equation & for $\mathrm{XHF}$ & $(\cos t=$ & $=\mathrm{G}=$ & price) & - comp & $\operatorname{var} \mathrm{XHF}$ & \\
\hline OSTYHF & pricing equation & for YHF & $(\cos t=$ & $=\mathrm{G}=$ & price) & - comp & var YHF & \\
\hline OSTXFH & pricing equation & for $X F H$ & (cost $=$ & $=\mathrm{G}=$ & price) & - comp & $\operatorname{var} \mathrm{XFH}$ & \\
\hline $\mathrm{FH}$ & pricing equation & for YFH & $(\cos t=$ & $=\mathrm{G}=$ & price) & - comp & var YFH & \\
\hline & pricing equation & for $W H$ & $(\cos t=$ & $=\mathrm{G}=$ & price) & - comp & var WH & \\
\hline OSTWF & pricing equation & for $W H$ & $(\cos t=$ & $=\mathrm{G}=$ & price) & - comp & var WF & \\
\hline $\mathrm{BH}$ & pricing equation & for $\mathrm{ABH}$ & $(\cos t=$ & $=\mathrm{G}=$ & price) & - comp & $\operatorname{var} \mathrm{ABH}$ & \\
\hline $\mathrm{BF}$ & pricing equation & for $\mathrm{ABF}$ & $(\cos t=$ & $=\mathrm{G}=$ & price) & - comp & $\operatorname{var} A B F$ & \\
\hline $\mathrm{ZH}$ & market clearing & equation & for $\mathrm{ZH}$ & I $-c$ & compleme & entary v & variable & $\mathrm{PZH}$ \\
\hline KTPZF & market clearing & equation & for ZF & $-c$ & compleme & entary v & variable & $\mathrm{PZF}$ \\
\hline KTPXH & market clearing & equation & for $\mathrm{XH}$ & $1-c$ & compleme & entary v & variable & $\mathrm{PXH}$ \\
\hline KTPYH & market clearing & equation & for YH & $1-c$ & compleme & entary v & variable & PYH \\
\hline KTPXF & market clearing & equation & for $X F$ & $-c$ & compleme & entary v & varia & PXF \\
\hline YF & market clearing & equation & for YF & $-c$ & compleme & entary v & variable & PYF \\
\hline $\mathrm{LH}$ & et clearing & equation & for LH & I $-c$ & compleme & entary v & variable & $\mathrm{PLH}$ \\
\hline MKTPLF & market clearing & equation & for $L F$ & $-c$ & compleme & entary v & variak & PLF \\
\hline IKTPWH & market clearing & equation & for $W H$ & $-c$ & compleme & entary v & variable & PWH \\
\hline MKTPWF & market clearing & equation & for $W F$ & $-c$ & compleme & entary v & variable & PWF \\
\hline & ar fo & & h: & a & & enditure & e - comp & $\mathrm{PABH}$ \\
\hline $\mathrm{BF}$ & ear for & nent & in $F:$ ta & axes & $\mathrm{s}=\operatorname{expe}$ & enditure & e - comp & $\mathrm{PABF}$ \\
\hline MKTENVH & lear en & nt in & $h:$ supp & ply & $=$ demar & id & - comp & PENVH \\
\hline MKTENVF & mkt clear enviro & nment in & f: supp & $\mathrm{ply}$ & $=$ demar & ad & - comp & PENVF \\
\hline
\end{tabular}

ICONSH income balance equation in h - complementary variable ICONSH

ICONSF income balance equation in f - complementary variable ICONSF

APOLRED pollution reduction = abatement by $h$ and $f$ - comp var POLRED APOL pollution generated by production by h and $f$ - comp var POL; 


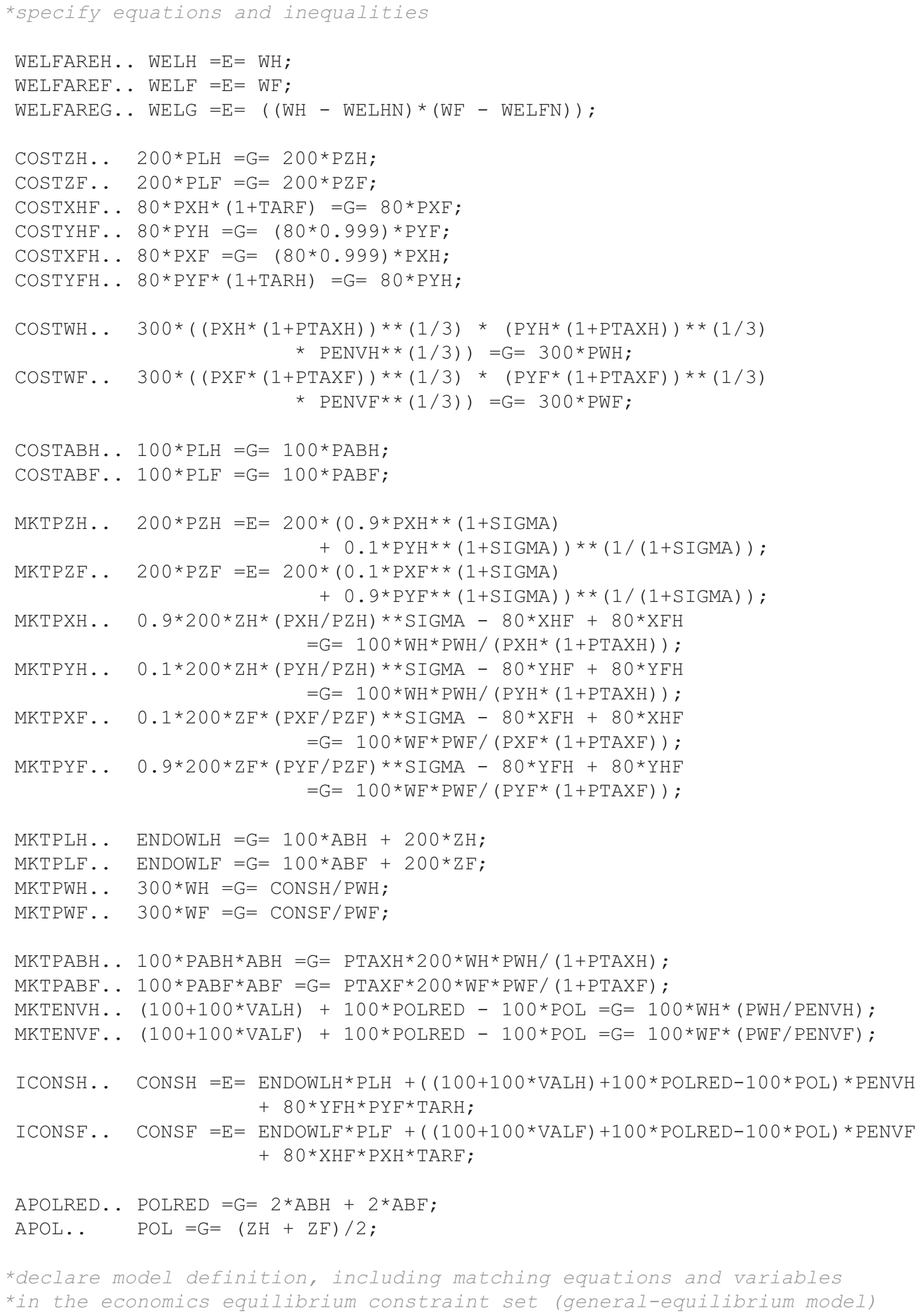




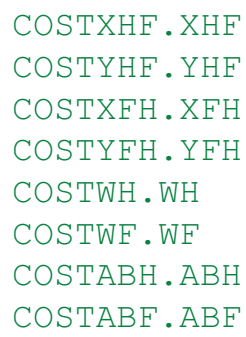

